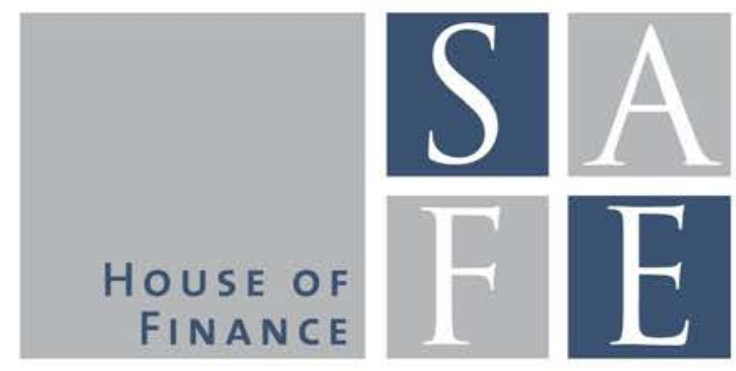

WORKING PAPER SERIES

Stefano Colonnello - Giuliano Curatola - Alessandro Gioffré

\title{
Pricing Sin Stocks: Ethical Preference vs. Risk Aversion
}

SAFE Working Paper No. 216

SAFE I Sustainable Architecture for Finance in Europe A cooperation of the Center for Financial Studies and Goethe University Frankfurt 


\section{Non-Technical Summary}

Several studies have shown that investments in companies involved in activities commonly perceived as sinful (for example, alcohol, tobacco, or gambling) are, on average, more profitable than investments in companies of comparable size but operating in sectors that are not considered sinful. The existing literature explains the observed return spread between sin and non-sin stocks by assuming the existence of a non-negligible number of investors who boycott investments in activities that are in conflict with their personal values. With a lower demand for sin stocks, investments in boycotted companies carry higher risk and, therefore, higher return ("sin premium").

In this paper, we present a different approach to explain the rise of the sin premium. We relax the assumption of boycott behavior as an inflexible norm adopted by some investors, and introduce a class of ethical preferences capable of disclosing the interplay between dividend payment and ethicalness. Our setting allows us to endogenize the sin premium as a combined effect of the degree of complementarity between ethicalness and gain opportunities, and the degree of risk aversion. Theoretically, we find that our model replicates the return and volatility spread between sin and non-sin stocks if either (i) investors have low risk aversion and treat dividend payment and ethicalness as substitute goods or (ii) investors have high risk aversion and consider dividend payment and ethicalness as complementary goods. To understand which one of the two scenarios described above is in line with the data, we use an additional piece of information, namely the dynamics of the return and volatility spread conditional on the dividend share of the sin stock.

Empirically, we study the relation between conditional moments and dividend payments using US data. We find that only a setting where dividends and ethicalness are complementary goods and investors are sufficiently risk averse (case (ii)) can explain the observed return and volatility spread between sin and non-sin (comparable) stocks.

Our analysis is important to overcome three limitations of the boycott risk approach. First, the adoption of ethical preferences restores centrality to diversification opportunities in price formation. Second, our theoretical setting is suitable to study the behavior of conditional moments. Third, our predictions can be easily tested because they are based on observable variables. 


\title{
Pricing Sin Stocks: Ethical Preference vs. Risk Aversion*
}

\author{
Stefano Colonnello ${ }^{\dagger}$ Giuliano Curatola ${ }^{\ddagger}$ Alessandro Gioffré ${ }^{\S}$
}

June 14, 2018

\begin{abstract}
We develop a model that reproduces the average return and volatility spread between sin and non-sin stocks. Our investors do not necessarily boycott sin companies. Rather, they are open to invest in any company while trading off dividends against ethicalness. We show that when dividends and ethicalness are complementary goods and investors are sufficiently risk averse, the model predicts that the dividend share of sin companies exhibits a positive relation with the future return and volatility spreads. Our empirical analysis supports the model's predictions.
\end{abstract}

JEL Classification: D51, D91, E20, G12

Keywords: Asset Pricing, General Equilibrium, Sin Stocks

*We would like to thank Marc Crummenerl, Lammertjan Dam, Marco Della Seta, Alexander Hillert, Michael Koetter, Timo Plaga, Patrick Roger, Vahid Saadi, Christian Schlag, Julian Thimme and seminar participants at the 26th International Rome Conference on Money, Banking and Finance, 15th Paris December Finance Meeting, and University of Zurich for insightful discussions and comments. Giuliano Curatola acknowledges the support from the Research Center SAFE, funded by the State of Hessen initiative for research LOEWE. Declarations of interest: none.

${ }^{\dagger}$ Otto-von-Guericke University Magdeburg and Halle Institute for Economic Research (IWH), Germany. E-mail: stefano.colonnello@iwh-halle.de.

${ }^{\ddagger}$ Goethe University Frankfurt, Germany. E-mail: curatola@safe.uni-frankfurt.de.

${ }^{\S}$ Corresponding author. University of Florence (Dipartimento di Scienze per l'Economia e l'Impresa, DISEI) and Research Center SAFE (Goethe University Frankfurt), Via delle Pandette 9, 50127, Firenze, Italy. E-mail: alessandro.gioffre@unifi.it. 


\section{Introduction}

The interest in socially responsible investments has been steadily growing in recent years. ${ }^{1}$ Individual and institutional investors increasingly seek profit opportunities that are concurrently consistent with their personal values and can boost social well-being. However, it is well documented that investments in stocks that promote social goals and ethical behavior underperform relative to those involved in activities that are generally considered sinful (such as alcohol, tobacco, and gambling industries). Several studies find that sin stocks yield (on average) higher returns than those of non-sin comparable stocks. This so-called "sin premium" is often rationalized by a "boycott" risk factor, namely, the risk that socially responsible investors refuse to hold stocks of sin companies (see Heinkel, Kraus, and Zechner, 2008; Hong and Kacperczyk, 2009; Luo and Balvers, 2017). ${ }^{2}$ As a result, sin companies are underpriced relative to non-sin companies and must promise higher returns to attract a large enough investor base.

In this paper, we relax the boycott assumption and suggest a more general approach to study the link between ethical behavior and stock prices. We assume that investors have preferences for ethical products but are also willing to hold all categories of stocks. Therefore, they do not boycott (ex-ante) any particular class of companies. Investors receive dividends from both sin and non-sin stocks and evaluate them according to their preferences for firms' ethicalness. We theoretically and empirically show that allowing for diversification opportunities across sin and non-sin stocks generates a new economic channel capable of explaining the unconditional (and conditional) return and volatility spreads between these categories of stocks.

\footnotetext{
${ }^{1}$ According to the US SIF Foundation's 2016 Report, from 1995 to 2016 the "SRI universe has increased nearly 14 -fold, a compound annual growth rate of 13.25 percent."

${ }^{2}$ The term "socially responsible investors" refers to agents who support investments in companies actively engaged in ethical themes such as environmental sustainability, social justice, gender equality, while avoiding companies whose business is related to addictive substances like tobacco, alcohol, gambling, etc.
} 
Our modeling approach allows us to overcome several limitations of the boycott risk story. First, assuming that a non-negligible group of investors refuses to hold sin stocks implies that diversification opportunities do not play an important role in price formation. Under the boycott assumption, socially responsible investors are indeed never attracted by arbitrarily high (expected) returns of stocks that are considered morally inappropriate or socially harmful. By contrast, in our model firm's ethicalness creates a precise economic role for the demand of diversification among stocks identified as either sinful or non-sinful. Second, the boycott risk literature typically focuses on the unconditional return spread between sin and non-sin stocks neglecting the conditional return spread, as well as the unconditional and conditional volatility spreads. ${ }^{3}$ Finally, versions of the CAPM with restricted investors (i.e., investors who boycott a given class of stocks) cannot be easily tested because equilibrium returns depend on a fraction of constrained agents and on their wealth share, i.e., non-observable quantities (Levy, 1978; Malkiel and Xu, 2006). Instead, our predictions can be directly tested because they are based on more easily observable variables.

In our model, agents have preferences for gain opportunities (dividends) and firms' responsible behavior (ethicalness). The role of substitutability between dividends and ethicalness is crucial. Dividends and ethicalness can be complementary (i.e., the marginal utility of an additional unit of the "non-sin dividend" is higher than the marginal utility of an additional unit of the "sin dividend"), or alternatively the two goods can be substitutes (i.e., the marginal utility of an additional unit of the sin dividend is higher than that of an additional unit of the non-sin dividend). In equilibrium, the return spread between sin and non-sin stocks depends on the marginal rate of substitution between dividends and ethicalness, which, in turn, depends on the interaction between dividend-ethicalness complementarity and risk aversion. We show that sin companies have higher average

\footnotetext{
${ }^{3}$ For example, Luo and Balvers (2017) show that the conditional version of their boycott risk model is rejected by the data.
} 
returns and volatility than non-sin companies in two cases:

i. When dividends and ethicalness are substitute goods and investors have low risk aversion (i.e., smaller than log utility), and

ii. When dividends and ethicalness are complementary goods and investors have high risk aversion (i.e., higher than log utility).

In both cases, the marginal rate of substitution between dividend payments and ethicalness is positive, which implies that investors would like to receive more dividends from non-sin companies than from sin companies. However, since dividend payments are beyond investors' control, the expected returns must adjust to offset the "ethical" costs of holding sin stocks. In line with the U.S. empirical evidence, our model produces the average positive return and volatility spreads between sin and non-sin stocks.

Cases i. and ii. suggest that two mutually exclusive preference specifications can explain the average return and volatility spreads between sin and non-sin stocks. However, these two settings have opposite predictions about the dynamics of moments conditional on the sin dividend share in the economy. Under case i., the dividend share exhibits a negative relation with return and volatility spreads. Conversely, under case ii., the dividend share exhibits a positive relation with return and volatility spreads. To understand which of the two preference specifications better explains the observed patterns in returns, we investigate the empirical relation between conditional moments and dividend payments. Using data on U.S. public companies, we provide evidence consistent with case ii. Therefore, a setting featuring complementary dividends and ethicalness along with sufficiently risk averse (i.e., more risk averse than log utility) investors can explain the observed behavior of the return spread between sin and non-sin (comparable) stocks. In addition, our model, which is endowed with such a preference specification, also performs well in capturing the unconditional and conditional volatility spreads between these two groups of stocks. 
The rest of the paper is organized as follows. In Section 2, we provide motivating evidence on the returns of sin stocks. In Section 3, we present a two-good general equilibrium model where agents' preferences also account for the perceived ethicalness of the consumed goods (i.e., dividends from sin and non-sin stocks). In Section 4, we test the empirical predictions of the model. Section 5 concludes.

\section{Background and motivation}

To study the return differential between sin and non-sin stocks, we follow the approach proposed by Hong and Kacperczyk (2009). We construct an equally-weighted portfolio of U.S. publicly traded companies involved in the production of alcoholic beverages, tobacco products, and gambling (sin companies). We analyze the returns of this portfolio compared to a portfolio of otherwise comparable non-sin companies (food, soda, entertainment, and dining industries) over the time period 1965Q1-2015Q4. ${ }^{4}$ The main rationale behind this classification is to create two portfolios of companies operating in similar sectors that differ only in the investors' assessment of company ethicalness that, in turn, depends on the type of consumption good produced. In this way, the return differential should only depend on the degree of ethicalness, provided that it matters to investors, and not on other issues related to industry characteristics. ${ }^{5}$ Table 1 shows that the average quarterly excess return on the sin portfolio is equal to $2.3 \%$ (Panel A), while the average quarterly excess return on the comparable portfolio is equal to $1.7 \%$ (Panel B). The sin portfolio also exhibits a higher standard deviation than that of the portfolio of comparable companies (12.0\% vs 11.2\%). Hong and Kacperczyk (2009) find similar results during the period 1965-2005, including higher excess returns (2.8\% vs. $0.75 \%)$ and higher standard deviation (9.73\% vs. $4.45 \%)$ for sin stocks. We find that the differential return of sin stocks is even larger for value-weighted portfolios (3.8\% vs. $2.9 \%$ quarterly),

\footnotetext{
${ }^{4}$ We provide further details on portfolio construction in Appendix C.

${ }^{5}$ See Hong and Kacperczyk (2009) for more details on the intuition behind this approach.
} 
while the difference in the standard deviation is similar to the case of equally-weighted portfolios (9.5\% vs. $8.7 \%)$.

Hong and Kacperczyk (2009) classify as sinful only those companies producing sin goods but not those involved in their distribution. We also build an extended sin portfolio that includes companies operating in the retail sector (Panel C). In this case, the difference between the quarterly returns of sin and non-sin stocks is smaller for the equally-weighted portfolios (1.8\% vs. 1.7\%), but of the same magnitude for the value-weighted portfolios (3.8\% vs. $2.9 \%$ ). Additional empirical evidence is provided by Fabozzi, Ma, and Oliphant (2008), who document an annualized excess return of sin stocks of approximately $11 \%$ with respect to the market over the period 1970-2007. The evidence of a sin premium is robust for different countries. Fabozzi et al. (2008) analyze 21 national markets (including European, U.S., and Asian markets) and Salaber (2007) considers European markets. ${ }^{6}$

Overall, this analysis suggests that in the U.S., sin companies pay on average higher returns than non-sin companies and are characterized by higher volatility. However, it is worth emphasizing that the evidence on the sin premium is heterogeneous across countries. In the U.S. and in Europe, we typically observe that institutional investors underweight sin stocks, which pay higher returns than non-sin stocks. By contrast, in other countries, such as some in the Asia Pacific region, we observe that ethical companies pay higher risk-adjusted returns even though institutional investors underweight sin stocks (Phillips, 2011; Durand, Koh, and Tan, 2013; Fauver and McDonald, 2014). In those countries, boycott behavior (directed at companies that are perceived as sinful) is thus unlikely to be the main force driving the return spread between sin and non-sin stocks. Other forces may drive the sign and magnitude of the observed return spread between sin and non-sin stocks. We propose a tractable and flexible general equilibrium

\footnotetext{
${ }^{6}$ It is important to mention that these two strands of literature typically differ in the benchmark used to compute the excess returns of sin stocks: Hong and Kacperczyk (2009) analyze the differences between a portfolio of sin stocks and a portfolio of comparable stocks while Fabozzi et al. (2008) study the excess return of sin stocks with respect to the aggregate market.
} 
model to explain the economic mechanism behind such patterns.

\section{The economy}

Our model is built on a continuous-time Lucas (1978) economy with an infinite horizon. There are two firms: A "sin" firm and a "non-sin" comparable firm indexed by " $s$ " and " $c$ ", respectively. ${ }^{7}$ The uncertainty is represented by a filtered probability space $\left(\Omega, \mathcal{F},\left\{\mathcal{F}_{t}\right\}, \mathbb{P}\right)$ on which we define a two-dimensional Brownian motion $B_{t}=\left(B_{s, t}, B_{c, t}\right)$ that captures production randomness over time.

\subsection{Consumption goods}

There are two perishable consumption goods, $i \in\{s, c\}$. A convex combination of the two consumption goods (with weights $\alpha$ and $1-\alpha$, respectively) serves as the numeraire. The price of the numeraire is normalized to unity and the relative prices of the two consumption goods are given by $p_{t}=\left(p_{s, t}, p_{c, t}\right)$. This choice of the numeraire is common in asset pricing models with multiple consumption goods (see, for instance, Pavlova and Rigobon, 2007). Consumption goods are produced by two firms according to the following production technology

$$
d D_{i, t}=D_{i, t}\left(\nu_{i} d t+\phi_{i} d B_{i, t}\right)
$$

where $D_{i, t}$ represents the total supply of good $i$, and $D_{i, 0}, \nu_{i}$ and $\phi_{i}$ are positive coefficients, with $i \in\{s, c\}$. In the Lucas' pure-exchange economy, $D_{i, t}$ represents both the supply of consumption good and the dividend of firm $i$. Therefore, when describing the implications of our theoretical framework, we use the terms consumption and dividend interchangeably. ${ }^{8}$ We assume that the two firms are characterized by different perceived ethicalness, which is represented by the parameter $\pi_{i}$, with $i \in\{s, c\}$. We assume that

\footnotetext{
${ }^{7}$ We use the terms "non-sin" and "non-sin comparable" interchangeably to refer to "c" firms.

${ }^{8}$ In the calibration exercise and empirical tests, we rely on the time-series of dividends paid by sin and non-sin companies.
} 
$\pi_{s}<\pi_{c}$, i.e., the degree of ethicalness of sin companies is smaller than that of non-sin companies. Note that in our framework the investors' judgment of company ethicalness depends on the consumption good produced by the company and, as a result, does not change over time. For example, a company producing whiskey will always be labeled as sin in our framework, while a company producing orange juice will always be labeled as non-sin or comparable, consistent with the original idea of Hong and Kacperczyk (2009) and with the empirical analysis of Section 4.

As will become clear later, two quantities are key in our theoretical model: The (timevarying) dividend share of sin companies, $d_{s}=\frac{D_{s, t}}{D_{s, t}+D_{c, t}}$, and their (constant) relative degree of ethicalness $c_{s}=\frac{\pi_{s}}{\pi_{s}+\pi_{c}}$. Note that as long as $c_{s}<0.5$ (i.e., the degree of ethicalness of sin companies is lower than that of comparable companies) the numerical values of $\pi_{s}$ and $\pi_{c}$ are not particularly relevant for our main message. In other words, one may also think of comparable (non-sin) stocks simply as companies with a higher degree of ethicalness than sin companies or, more generally, as a portfolio comprising any stocks in the market other than sin stocks. This interpretation does not affect the analytical results presented below. However, following the original scheme in Hong and Kacperczyk (2009), we interpret comparable (non-sin) companies as those involved in the food, soda, fun, and meals industries. This interpretation makes our theoretical model consistent with our empirical analysis.

\subsection{Ethicalness}

Our main departure from the traditional asset pricing literature is the assumption that investors' utility not only depends on asset payoffs but also on firms' ethicalness. This possibility has already been suggested by the existing literature to justify the return spread between sin and non-sin companies. For instance, Beal, Goyen, and Philips (2005) on p. 72 argue that "including the perceived level of ethicality of an investment in the 
investor's utility function" is one possible way to incorporate ethicalness into a theoretical framework. Fama and French (2007) on p. 675 argue that socially responsible investors might also get utility from firm characteristics (such as social behavior) above and beyond the payoff provided by the asset; therefore, they might refuse, for example, to hold "stocks of tobacco companies or gun manufacturers."

More generally, the decision theory literature recognizes the importance of multiattribute utility functions. Extensive research on such functions has been done with applications ranging form engineering to the efficient usage of energy and water resources (Wallenius, Dyer, Fishburn, Steuer, Zionts, and Deb, 2008). However, applications to finance are not common. Bollen (2007) suggests that investors may have a multi-attribute utility function: A standard attribute capturing the asset payoff and non-standard attributes depending on the firm's social behavior. If investors get utility from non-monetary payoffs, then stock prices and returns should depend on the investors' subjective valuation of firms and not only on the firm's fundamentals. Frijns, Koellen, and Lehnert (2008) show that the risk return trade-off is not the sole determinant of portfolio allocations. Other factors, such as investor sentiment and individual characteristics, are also important and should enter the utility function of investors. Such a modeling choice can also be motivated by the work of Statman, Fisher, and Anginer (2008), who use the Fortune Magazine rating to distinguish between "admired" and "spurned" stocks and find that spurned stocks pay higher returns than admired stocks. These results suggest that subjective (non-pecuniary) attributes may play a role in determining asset prices and should then be included in the investors' utility function.

If ethical concerns have price implications as shown by Hong and Kacperczyk (2009) and Hong and Kostovetsky (2012), then it is natural to assume that they should enter the investors' utility function. The same conclusion is reached the literature on corporate 
social responsibility. ${ }^{9}$ Yet, excluding the general theoretical considerations of Beal et al. (2005), little to no guidance exists on how to incorporate company ethicalness into the investors' utility function, especially in a fully dynamic asset pricing model. In this paper, we try to fill this gap in the literature and suggest a simple multi-attribute utility function to study how the interaction between different attributes (monetary payoff and ethicalness) influences the return and volatility spreads between sin and non-sin stocks.

The key feature of the utility we introduce is the complementary/substitutability between firms' monetary payoff and ethicalness, which in our model is governed by one parameter only. The complementarity between monetary payoffs and ethicalness may matter for the investors' relative evaluation of sin companies because the firm's ethicalness, or more generally its corporate social responsibility, can be interpreted as a public good. For instance, Kotchen (2006) builds a model where individuals' utility depends on a private good and a public good, which he interprets as environmental quality. He shows that the complementary/substitutability between private consumption and public goods is key to understand the effect of the introduction of a green technology on the private provision of the public good and its welfare implications.

Before proceeding, it is worth pointing out that our analysis is in the spirit of Hong and Kacperczyk (2009), and therefore, the concept of ethicalness used in our paper differs from the more general one of corporate social responsibility (CSR). ${ }^{10}$ The classification of sin stocks focuses on one facet of CSR, namely, the ethical nature of firms' consumption goods. Companies supplying alcoholic beverages, tobacco products, and gambling services are typically labeled sinful because the demand of such products is intimately related to individuals' weaknesses. ${ }^{11}$ The concept of CSR goes beyond the ethical assessment on

\footnotetext{
${ }^{9}$ See the recent surveys of Kitzmueller and Shimshack (2012) and Schmitz and Schrader (2015).

${ }^{10} \mathrm{CSR}$ is generally measured using KLD ratings (now known as MSCI-ESG STATS) or similar datasets. For instance, Bansal, Wu, and Yaron (2016) investigate the relation between time-varying investor preferences and the risk and return of firms depending on their CSR ratings.

${ }^{11}$ Think of the five thieves: Lust, rage, greed, attachment, conceit.
} 
firms' outputs and comprises additional social dimensions such as consumer protection practices, corporate governance, environmental attitude, and philanthropic behavior. To understand the differences between ethicalness and CSR, consider the Volkswagen emissions scandal of 2015. The CSR score of Volkswagen has been negatively affected by this event. ${ }^{12}$ However, Volkswagen, as a car producer, is not a sin company according to the classification of Hong and Kacperczyk (2009). Moreover, CSR indexes are typically time-varying (as the Volkswagen case suggests) and may be driven by firms' performance or missions. Conversely, the classification of sin companies depends on the nature of the consumption goods produced, which is to a large extent time-invariant.

On a related note, the sin stock classification reduces the potential endogeneity concerns for our empirical exercise. In fact, testing our model's predictions requires an analysis of the relation between the stock returns and dividend payments of sin and nonsin companies. The decision to operate in a sinful/non-sinful industry is generally taken as of the foundation of the firm and can arguably be regarded as exogenous to current payout decisions. This is unlikely to be case for CSR policy, which is determined jointly with the payout policy. An econometric approach that classifies sin and non-sin companies using CSR indexes and that tries to explain the expected return differential between the two categories of stocks using dividend payments is likely to be affected by endogeneity issues. Thus, our ethicalness classification of companies is based only on the ethical connotation of their produced goods (which is generally accepted among investors) rather than on their CSR rating.

\footnotetext{
${ }^{12}$ For instance, on October 6, 2015 Volkswagen Group was removed from the Dow Jones Sustainability Indices.
} 


\subsection{Preferences}

Investors derive utility from both the consumption goods $c_{i, t}$ (i.e., the dividends) and the perceived degree of ethicalness $\pi_{i}$ of sin and non-sin firms, with $i \in\{s, c\}$ :

$$
U\left(c_{s, t}, c_{c, t}\right)=\pi_{s}^{\beta}{\frac{\left(c_{s, t}\right)}{1-\gamma}}^{1-\gamma}+\pi_{c}^{\beta}{\frac{\left(c_{c, t}\right)}{1-\gamma}}^{1-\gamma} .
$$

Here, $\gamma$ represents the relative risk aversion of investors, while the parameter $\beta$ governs the complementarity between ethicalness and dividend consumption. If $\beta<0$, ethicalness and dividends are substitute goods, which means that the marginal utility of consuming the firm's dividend is a decreasing function of $\pi_{i}$. In other words, a high degree of ethicalness produces the same qualitative effects as high consumption, i.e., it reduces the marginal utility of consuming the firm's dividend. If $\beta>0$, ethicalness and dividends are complementary goods, that is an increase in the ethicalness perception has the same qualitative effect as low consumption, i.e., it increases the marginal utility of consuming the firm's dividend. ${ }^{13}$ The utility function in (2) is computationally tractable, which, in turn, lets the economic mechanism behind the stock return spread emerge clearly and in closed form from the model. ${ }^{14}$

The framework is further motivated by the distinction between individual and institutional investors, such as mutual funds, pension funds, and foundations. Institutional investors typically operate under guidelines that sometimes may lead to the exclusion of unethical companies from their portfolios. Consistently, Hong and Kacperczyk (2009)

\footnotetext{
${ }^{13}$ The link between $\beta$ and the dividend-ethicalness complementarity is given by their cross-derivative:

$$
\frac{\partial^{2} U}{\partial \pi_{s} \partial c_{s, t}}=\beta \pi_{s}^{\beta-1} c_{s, t}^{-\gamma}, \quad \frac{\partial^{2} U}{\partial \pi_{c} \partial c_{c, t}}=\beta \pi_{c}^{\beta-1} c_{c, t}^{-\gamma},
$$

and the sign of the derivatives above depends on $\beta$ only.

${ }^{14}$ Other preference specifications are possible here. For example, the function in Equation (2) is additive in the utility received from consuming the two dividends. Alternatively, other forms of aggregation between the two dividends can be adopted, such as, for example, the CES aggregator. Moreover, we assume that the parameters in (2) that govern complementarity $(\beta)$ and risk aversion $(\gamma)$ are invariant across the two consumption items, while, more generally, their values could vary across goods.
} 
find that institutional investors underweight sin stocks, and thus shareholdings of sin stocks tend to be concentrated among individual investors.

However, little is known about ethical preferences of individual investors. Hong and Kostovetsky (2012) suggest that individual investors may dislike sin stocks for two reasons. First, they may shy away from companies producing goods that they spurn. To some extent, this corresponds to a boycott behavior towards products that are unwanted. However, this argument disregards the trade-off between ethical behavior and monetary payoffs. Thus the question arises: How much cash flows are investors willing to sacrifice for a higher degree of investment ethicalness? Moreover, Fabozzi et al. (2008) argue that, although investors normally claim that they do not invest in companies that are assessed unethical, "the validity of the responses could be questioned because of the desire of those polled to respond in a politically correct fashion, and not necessarily putting their money where their mouths are (p. 83)." Lemieux (2003) reaches similar conclusions. The second reason why individual investors might display preferences for ethical companies concerns valuation bias. Investors may be persuaded that companies following principles that are inconsistent with their values are also less profitable. Although this argument may be appealing, it is not clear why individual investors do not learn from past performance and accordingly correct their bias, given that sin stocks perform better (on average) than non-sin stocks.

Hence, boycott behavior appears to be more consistent with the strategies of institutional investors rather than with those of individual investors. In our model, investors hold both stocks and their ethical preferences determine equilibrium stock returns. Such a setting aims at capturing the effect of individual investors' ethical preferences for asset prices, stock returns, and the standard deviation of both sin and non-sin companies. This approach is in line with the empirical findings of Bansal et al. (2016), who conclude that observed differences between good and bad stocks are more attributable to the demand 
side than to the supply side.

\subsection{Financial market}

There are three securities traded on the market: Two risky assets (stocks) in positive supply of one unit and one risk-free asset (bond) in zero-net supply. Stock $i$ represents the claim to dividend $i$ paid in units of good $i$, where $i \in\{s, c\}$. The stock price, denoted by $S_{i, t}$, evolves as follows

$$
d S_{i, t}+p_{i, t} D_{i, t} d t=S_{i, t} \mu_{i, t} d t+S_{i, t} \sum_{j \in\{s, c\}} \sigma_{j, t}^{i} d B_{j, t}
$$

The price of the risk-free asset (in term of the numeraire) satisfies

$$
S_{0, t}=e^{\int_{0}^{t} r_{s} d s}
$$

for some risk-free rate of return $r_{t}$. The variables $\mu_{i, t}, \sigma_{j, t}^{i}, r_{t}, p_{i, t}$, for $i, j \in\{s, c\}$, are to be endogenously determined in equilibrium.

\subsection{The competitive equilibrium}

\subsubsection{Optimal consumption}

The representative investor maximizes utility subject to the supply constraints:

$$
\begin{array}{r}
\max _{c_{s, t}, c_{c, t}} \mathbb{E} \int_{0}^{\infty} e^{-\rho t}\left[\pi_{s}^{\beta} \frac{\left(c_{s, t}\right)^{1-\gamma}+\gamma}{1-\gamma}+\pi_{c}^{\beta} \frac{\left(c_{c, t}\right)^{1-\gamma}}{1-\gamma}\right] d t \\
\text { s.t. } \quad c_{s, t} \leq D_{s, t} \quad \text { and } \quad c_{c, t} \leq D_{c, t} .
\end{array}
$$

In equilibrium, demand and supply of consumption and financial securities are equal to each other. This means that our representative agent has to hold the entire supply of risky assets and consume the total supply of consumption/dividend. Therefore, there is no 
room for boycotting assets or consumption goods of sin companies, and stock returns are only determined by the investor's preferences for ethical companies relative to unethical companies. $^{15}$

We solve the problem using the martingale method of Karatzas, Lehoczky, and Shreve (1987). The optimal consumption plan is determined by the first-order conditions

$$
e^{-\rho t} \pi_{s}^{\beta} c_{s, t}^{-\gamma}=\lambda_{t} p_{s, t}, \quad e^{-\rho t} \pi_{c}^{\beta} c_{c, t}^{-\gamma}=\lambda_{t} p_{c, t}
$$

where $\lambda_{t}$ is the state price density (i.e., the Arrow-Debreu price of one unit of the numeraire delivered at time $t$ in state $\omega \in \Omega$ ), while $p_{i, t}$ is the relative price of good $i \in\{s, c\}$. The term $\lambda_{t} p_{i, t}$ represents the price of one unit of good $i$ at time $t$ in state $\omega \in \Omega$. Prices $\lambda_{t}$ and $p_{i, t}$ are derived by imposing the market clearing conditions on consumption and are reported below.

Proposition 1. In our economy with separable utility (2), the equilibrium state price density and relative prices are given by

$$
\begin{aligned}
& \lambda_{t}=e^{-\rho t}\left[\alpha \pi_{s}^{\beta} D_{s, t}^{-\gamma}+(1-\alpha) \pi_{c}^{\beta} D_{c, t}^{-\gamma}\right], \\
& p_{s, t}=e^{-\rho t} \frac{\pi_{s}^{\beta} D_{s, t}^{-\gamma}}{\lambda_{t}}, \quad p_{c, t}=e^{-\rho t} \frac{\pi_{c}^{\beta} D_{c, t}^{-\gamma}}{\lambda_{t}} .
\end{aligned}
$$

Moreover, we have that

$$
\begin{aligned}
& \text { - If } \beta<0, \frac{\partial p_{s, t}}{\partial\left(\pi_{c} / \pi_{s}\right)}>0 \text { and } \frac{\partial p_{c, t}}{\partial\left(\pi_{c} / \pi_{s}\right)}<0 ; \\
& \text { - If } \beta>0, \frac{\partial p_{s, t}}{\partial\left(\pi_{c} / \pi_{s}\right)}<0 \text { and } \frac{\partial p_{c, t}}{\partial\left(\pi_{c} / \pi_{s}\right)}>0 ; \\
& \text { - } \frac{\partial p_{s, t}}{\partial\left(D_{s, t} / D_{c, t}\right)}<0 \text { and } \frac{\partial p_{c, t}}{\partial\left(D_{s, t} / D_{c, t}\right)}>0 .
\end{aligned}
$$

\footnotetext{
${ }^{15} \mathrm{~A}$ similar assumption is made by Dam and Heijdra (2011) who build a general equilibrium model where agents invest in "clean" assets and "dirty" assets (i.e., assets issued by firms that pollute). In addition, investors feel responsible for financing production technologies that pollute. In this framework, Dam and Heijdra (2011) study how responsible behavior and fiscal policies interact in reducing the level of environmental pollution.
} 
Proof. See Appendix A.

The price of each risky asset is computed as the present value of the dividend stream paid by the asset, discounted using the state-price density and the relative prices determined above. Formally, we have

$$
\begin{aligned}
& S_{s, t}=\mathbb{E}_{t} \int_{t}^{\infty}\left[\frac{\lambda_{u}}{\lambda_{t}} p_{s, u} D_{s, u} d u\right]=p_{s, t} D_{s, t} \mathbb{E}_{t} \int_{t}^{\infty}\left[e^{-\rho(u-t)}\left(\frac{D_{s, u}}{D_{s, t}}\right)^{(1-\gamma)}\right] d u, \\
& S_{c, t}=\mathbb{E}_{t} \int_{t}^{\infty}\left[\frac{\lambda_{u}}{\lambda_{t}} p_{c, u} D_{c, u} d u\right]=p_{c, t} D_{c, t} \mathbb{E}_{t} \int_{t}^{\infty}\left[e^{-\rho(u-t)}\left(\frac{D_{c, u}}{D_{c, t}}\right)^{(1-\gamma)}\right] d u .
\end{aligned}
$$

Under the assumption of a log-normal dividend process, the prices of sin and non-sin stocks are given in the proposition below.

Proposition 2. Stock prices of sin and non-sin assets are given by

$$
S_{s, t}=\frac{p_{s, t} D_{s, t}}{\Gamma_{s}}, \quad S_{c, t}=\frac{p_{c, t} D_{c, t}}{\Gamma_{c}}
$$

where $\Gamma_{1}$ and $\Gamma_{2}$ are defined by

$$
\begin{aligned}
& \Gamma_{s}:=\rho+(\gamma-1)\left(\nu_{s}-\frac{\phi_{s}^{2}}{2}\right)-\frac{1}{2}(1-\gamma)^{2} \phi_{s}^{2} \\
& \Gamma_{c}:=\rho+(\gamma-1)\left(\nu_{c}-\frac{\phi_{c}^{2}}{2}\right)-\frac{1}{2}(1-\gamma)^{2} \phi_{c}^{2}
\end{aligned}
$$

and parameters are such that $\Gamma_{s}>0$ and $\Gamma_{c}>0$.

Proof. See Appendix A.

Hong and Kacperczyk (2009) find that stocks of sin companies are cheaper than those of non-sin companies. They suggest that the reason for this result can be found in the 
responsible behavior of investors who underweight stocks of sin companies, thus reducing their price. Our model takes into account this aspect. Using the equilibrium prices in Proposition 2, in fact, we obtain

$$
\begin{aligned}
\log \left(S_{s, t}\right)-\log \left(S_{c, t}\right)= & \beta\left[\log \left(\pi_{s}\right)-\log \left(\pi_{c}\right)\right]+(1-\gamma)\left[\log \left(D_{s, t}\right)-\log \left(D_{c, t}\right)\right] \\
& +\log \left(\Gamma_{c}\right)-\log \left(\Gamma_{s}\right) .
\end{aligned}
$$

Equation (9) suggests that the price differential between sin and non-sin companies depends on current dividend payments (second term on the right-hand side) and dividend fundamentals (third term on the right-hand side). The first term on the right-hand side of equation (9) plays a key role in our analysis. To see why, note that by assumption, $\log \left(\pi_{s}\right)-\log \left(\pi_{c}\right)<0$. Therefore, $\beta<0$ implies that, ceteris paribus, sin companies are worth more than non-sin companies, while, conversely, $\beta>0$ implies that non-sin companies are worth more than sin companies. The reason for this result lies in the implications of complementarity between ethicalness and consumption for the marginal utility of consumption. If $\beta>0$, the marginal utility of consumption increases with the perceived degree of ethicalness $\pi$. Therefore, the consumption of dividends paid by non-sin companies is worth more than that paid by sin companies, which implies that stocks of non-sin companies are more expensive than those of sin companies, all other things being equal.

However, seeking out for firms ethicalness is not the only determinant of stock prices. Risk aversion is also key and its magnitude determines the impact of dividend payments on stock prices. An increase in the dividend paid by sin companies (relative to that paid by non-sin companies) raises the expected cash-flow of sin companies (as compared to that of non-sin companies), and, at the same time, increases the discount rates applied to dividends of sin companies relative to that applied to dividends of non-sin companies (i.e., 
$p_{s, t}$ decreases and $p_{c, t}$ increases). For $\gamma>1$, the discount rate rises faster than expected cash-flows, so the price of sin stocks declines relative to the price of non-sin stocks. When $\gamma=1$, the effects from discount rate and cash-flow exactly offset each other and dividend payments do not affect stock prices.

The complementarity between dividend and ethicalness also has important implications for the conditional return spread between sin and non-sin stocks.

Proposition 3. The prices of the risky assets are driven by the following dynamics

$$
\begin{aligned}
\frac{d S_{s, t}}{S_{s, t}}= & \left.\left\{\nu_{s}-(1-\alpha) \gamma p_{c, t} \Lambda_{t}-(1-\alpha) p_{c, t} \gamma \phi_{s}^{2}\right]\right\} d t+\left[1-(1-\alpha) \gamma p_{c, t}\right] \phi_{s} d B_{s, t} \\
& +(1-\alpha) p_{c, t} \gamma \phi_{c} d B_{c, t} \\
\frac{d S_{c, t}}{S_{c, t}}= & {\left[\nu_{c}+\alpha \gamma p_{c, t} \Lambda_{t}+\alpha p_{s, t} \gamma \phi_{c}^{2}\right] d t-\alpha \gamma p_{s, t} \phi_{s} d B_{s, t}+\left[1+\alpha \gamma p_{s, t}\right] \phi_{c} d B_{s, t}, }
\end{aligned}
$$

with

$$
\Lambda_{t}:=\nu_{s}-\nu_{c}+\phi_{c}^{2}+\frac{1}{2}(\gamma-1)\left(\phi_{s}^{2}+\phi_{c}^{2}\right)-(1-\alpha) \gamma p_{c, t}\left(\phi_{s}^{2}+\phi_{c}^{2}\right)
$$

Proof. See Appendix A.

Results in Proposition 3 allow us to derive the conditional expected returns and the return spread between sin and non-sin stocks.

Proposition 4. The risk premia of the two risky assets are given by

$$
\begin{aligned}
& \mu_{s, t}-r_{t}=(1-\alpha)^{2} p_{c, t}^{2} \gamma^{2} \phi_{c}^{2}+\alpha p_{s, t} \gamma \phi_{s}^{2}\left[1-(1-\alpha) \gamma p_{c, t}\right] \\
& \mu_{c, t}-r_{t}=\alpha^{2} p_{s, t}^{2} \gamma^{2} \phi_{s}^{2}+(1-\alpha) p_{c, t} \gamma \phi_{c}^{2}\left[1-\alpha \gamma p_{s, t}\right]
\end{aligned}
$$


and the return spread between the two assets reads as

$$
\mu_{s, t}-\mu_{c, t}=\gamma(1-\gamma)\left[\alpha p_{s, t} \phi_{s}^{2}-(1-\alpha) p_{c, t} \phi_{c}^{2}\right]
$$

Proof. See Appendix A.

The return spread between sin and non-sin stocks depends on the weighted average of the standard deviation of dividends' growth rates $\left(\phi_{s}^{2}\right.$ and $\left.\phi_{c}^{2}\right)$, where the weights $\left(\alpha p_{s}\right.$ and $\left.(1-\alpha) p_{c}\right)$ depend on the contribution of the stocks to the total value of the consumption basket. These weights are time-varying and depend on dividend payments. From Proposition 1, it follows that the relative value of each dividend $\left(p_{s, t}\right.$ and $\left.p_{c, t}\right)$ decreases with its relative supply, and therefore the contribution of dividend risk $\left(\phi_{s}^{2}\right.$ and $\left.\phi_{c}^{2}\right)$ to the return spread decreases as the dividend paid by the company increases. From equation (10), we see that the impact of dividend payments on the return spread through the relative prices $p_{s, t}$ and $p_{c, t}$ depends on the risk aversion. Given that $\frac{\partial p_{s, t}}{\partial\left(D_{s, t} / D_{c, t}\right)}<0$ and $\frac{\partial p_{c, t}}{\partial\left(D_{s, t} / D_{c, t}\right)}>0$, the return spread between sin and non-sin stocks decreases with the dividend paid by sin companies relative to that of comparable companies (i.e., $\frac{D_{s, t}}{D_{c, t}}$ ) when $\gamma<1$, and increases otherwise. This result hinges on the trade-off between the discount rate channel and the cash-flow channel illustrated in equation (9). When $\gamma<1$ $(\gamma>1)$, the price spread between sin and non-sin stocks increases (decreases) with $\frac{D_{s, t}}{D_{c, t}}$, and therefore the expected return spread declines (increases).

The conditional return spread between sin and non-sin stocks also depends on firms' ethicalness. To see how, assume first that the two companies are the same with respect to any attributes and also pay the same dividends. In this case, $\mu_{s, t}-\mu_{c, t}=0$. What happens if the degree of ethicalness of one firm becomes larger than that of the other? Given the empirical evidence, one would expect that the return spread increases when $\pi_{c}$ 
increases as compared to $\pi_{s}$, that is $\frac{\partial\left(\mu_{s, t}-\mu_{c, t}\right)}{\partial\left(\pi_{c} / \pi_{s}\right)}>0$. Results in Proposition 1 imply

$$
\frac{\partial\left(\mu_{s, t}-\mu_{c, t}\right)}{\partial\left(\pi_{c} / \pi_{s}\right)}=(1-\gamma) \gamma\left[\alpha \frac{\partial p_{s, t}}{\partial\left(\pi_{c} / \pi_{s}\right)} \phi_{s}^{2}-(1-\alpha) \frac{\partial p_{c, t}}{\partial\left(\pi_{c} / \pi_{s}\right)} \phi_{c}^{2}\right]
$$

Therefore, the following cases may occur:

1. $\beta=0$ and/or $\gamma=1$ : In this case, $\frac{\partial\left(\mu_{s, t}-\mu_{c, t}\right)}{\partial\left(\pi_{c} / \pi_{s}\right)}=0$ and the firms' ethicalness has no impact on stock returns.

2. $\beta<0$ : In this case, $\frac{\partial p_{s, t}}{\partial\left(\pi_{c} / \pi_{s}\right)}>0$ and $\frac{\partial p_{c, t}}{\partial\left(\pi_{c} / \pi_{s}\right)}<0$ (Proposition 1) and thus

$$
\frac{\partial\left(\mu_{s, t}-\mu_{c, t}\right)}{\partial\left(\pi_{c} / \pi_{s}\right)}\left\{\begin{array}{l}
<0 \text { if } \gamma>1 \\
>0 \text { if } \gamma \in(0,1) .
\end{array}\right.
$$

3. $\beta>0$ : In this case, $\frac{\partial p_{s, t}}{\partial\left(\pi_{c} / \pi_{s}\right)}<0$ and $\frac{\partial p_{c, t}}{\partial\left(\pi_{c} / \pi_{s}\right)}>0$ (Proposition 1) and thus

$$
\frac{\partial\left(\mu_{s, t}-\mu_{c, t}\right)}{\partial\left(\pi_{c} / \pi_{s}\right)} \begin{cases}<0 & \text { if } \gamma \in(0,1) \\ >0 & \text { if } \gamma>1 .\end{cases}
$$

In summary, expected returns decrease with the firm's degree of ethicalness if $\beta<0 \wedge$ $\gamma<1$ or $\beta>0 \wedge \gamma>1$. To understand these results, we need to go back to the basic trade-off between ethicalness and dividend payment introduced in our framework. The total change in the utility function associated with changes in dividends and ethicalness of firm $i$ reads

$$
\Delta U=\beta \pi_{i}^{\beta-1}{\frac{\left(c_{i, t}\right)}{1-\gamma}}^{1-\gamma} \Delta \pi_{i}+\pi_{i}^{\beta} c_{i, t}^{-\gamma} \Delta c_{i}
$$

For $\Delta U=0$, the desired marginal rate of substitution between dividend and ethicalness 
of firm $i$ is thus given by

$$
M R S_{i}=\frac{\Delta c_{i}}{\Delta \pi_{i}}=-\frac{\beta}{1-\gamma} \frac{c_{i, t}}{\pi_{i}}=A \frac{c_{i, t}}{\pi_{i}}
$$

The key point is the sign of the constant $A=-\frac{\beta}{1-\gamma}$. $A>0$, when $\beta<0 \wedge \gamma<1$ or when $\beta>0 \wedge \gamma>1$. If this occurs, then investors would like to receive higher dividends when the degree of ethicalness increases, but they have no influence on firms' ethicalness and dividend payments, which are both decided by firms. Therefore, investors will ask for a premium as a reward for the risk of holding large dividends received from companies with a low degree of ethicalness. This explains why sin companies tend to pay, ceteris paribus, higher returns than non-sin companies when $\beta<0 \wedge \gamma<1$ or $\beta>0 \wedge \gamma>1$, and lower returns otherwise. This simple mechanism is also flexible. If $\beta<0 \wedge \gamma>1$ or $\beta>0 \wedge \gamma<1$, the model generates opposite predictions, that is, sin stocks will have on average lower returns than ethical stocks.

The mechanism above builds on the investors' valuations of firms' intermediate dividends/cash flows. Similar conclusions in a different framework are reached by Albuquerque, Koskinen, and Zhang (Forthcoming). A crucial role in their model, which features a production economy with socially and non-socially responsible firms, is played by the share of consumers' expenditures spent on responsible goods (non-sin goods). When the share of responsible goods is sufficiently small, responsible firms have lower systematic risk and higher valuations than non-responsible firms. Our approach differs from theirs in one important aspect. We build an endowment economy and focus on investors' behavior. Their focus is on firms' choices. Although the respective approaches and frameworks are different, the two papers share the important conclusion that the return differential between sin and non-sin stocks depends both on investors' preferences and the diversification risk induced by the consumption/dividend stream of sin and non-sin firms. 
Similarly, Baker, Hollifield, and Osambela (2018) consider a framework where investors choose between ethical (i.e., non-polluting) and unethical (i.e., polluting) firms. Ethical investors realize that higher dividends of polluting firms come at the cost of higher pollution, which reduces their utility. Therefore, the negative externalities of production directly affect investors' ability to diversify between the dividends of the two companies. In this framework, they analyze the ability of taxes, coordination mechanisms, and green derivatives to reduce aggregate pollution.

\subsection{Quantitative implications}

\subsubsection{Calibration}

To assess whether our framework is capable of providing a realistic qualitative description of the return spread between sin and non-sin stocks, we first need to calibrate the model. As a benchmark case, we consider a symmetric economy where the two firms have the same fundamentals (i.e., $\nu_{s}=\nu_{c}$ and $\phi_{s}=\phi_{c}$ ) and only differ in the realized dividend payments. To calibrate the dividend process, we use the average growth rate and the standard deviation of the total payout of sin and non-sin comparable companies (Table 1). Empirical estimates suggest that $\nu_{s}=4 \times 0.010, \nu_{c}=4 \times 0.006, \phi_{s}=\sqrt{4} \times 0.156$, and $\phi_{c}=\sqrt{4} \times 0.098$. To calibrate the symmetric economy, we take the mean of the above estimates, that is, we set $\nu_{s}=\nu_{c}=\frac{4 \times 0.010+4 \times 0.006}{2}$ and $\phi_{s}=\phi_{c}=\frac{\sqrt{4} \times 0.156+\sqrt{4} \times 0.098}{2}$. We choose $\alpha=1-\alpha=0.5$ in the symmetric economy. In the asymmetric economy, parameters are set equal to their empirical counterpart and we choose $\alpha=.18$ according to the average dividend share of sin companies (Table 1, Panel D). ${ }^{16}$ Our results also depend on relative ethicalness $c_{s}=\frac{\pi_{s}}{\pi_{s}+\pi_{c}}$. The only restriction here is $\pi_{s}<\pi_{c}$, which implies $0 \leq c_{s} \leq 0.5$. Therefore, to analyze conditional moments, we consider three

\footnotetext{
${ }^{16}$ This calibration is in the spirit of Pavlova and Rigobon (2007) They consider a two-country economy where the numeraire is a convex combination of the price of the two internationally traded good. The weight of the numeraire basket is calibrated according to the average GDP share of the two countries.
} 
values of relative ethicalness $c_{s}=[0.1,0.3,0.5]$. When computing average returns, we use $c_{s}=0.3$

Concerning the preference parameters $\beta$ and $\gamma$, we implement our analysis within a range of parameters selected to illustrate the economic mechanism at work in the model. Our theoretical predictions suggest that we should observe different patters of returns depending on whether $\beta<0 \wedge \gamma<1$ or $\beta>0 \wedge \gamma>1$. Since we consider risk averse agents, the natural lower bound for the risk aversion parameter $\gamma$ is 0 . Therefore, we use two values of $\gamma$, namely $\gamma=0.5$ and $\gamma=3$, which are in line with the usual estimates of risk aversion (see Benartzi and Thaler, 1995; Bliss and Panigirtzoglou, 2004). By contrast, there are no available estimates of $\beta$, the complementarity between dividends and ethicalness. Hence, we select a wide range of values centered at zero. This allows us to show how the behavior of stock returns varies with the sign of $\beta$. Precisely we consider $\beta \in[-20,20]$.

Conditional returns reported in Figure 1 and 2 are computed according to Proposition 4. The conditional standard deviation is also derived in closed form and reported in Appendix A. The results for the asymmetric economy are very similar and presented in Appendix B.

\subsubsection{Properties of stock returns}

Figure 1 and Figure 2 show the conditional return and volatility spreads between sin and non-sin stocks in the symmetric economy as a function of the dividend share of sin stocks, which we denote as $d_{s}=\frac{D_{s}}{D_{s}+D_{c}}$. As explained above, the dynamics of the conditional spreads is affected by investors' risk aversion. When investors are more risk averse than $\log$ utility, the discount factor rises faster than expected cash-flows, and therefore prices decrease when dividends increase. As a result, an increase in the dividend paid by sin stocks (relative to the dividend paid by non-sin stocks) reduces the current price of sin 
stocks relative to the price of non-sin stocks and, thus, raises future expected returns of sin stocks as compared to that of non-sin stocks. This mechanism implies that the conditional return volatility spreads between sin and non-sin stocks increase with the dividend share of sin stocks (Figure 1). When instead investors are less risk averse than log utility, the effect of an increase in dividend payments on expected cash-flows dominates the discount rate effect and, thus, prices increase following an increase in dividend payments. As a result, when the dividend share of sin stocks increases, the price of sin stock increases relative to the price of non-sin stocks, and the return spread between sin and non-sin stocks decreases (Figure 2). Results for the asymmetric economy are very similar and reported in Appendix B.

A novel aspect in our framework related to the effects of the perceived ethicalness, summarized by the relative variable $c_{s}=\frac{\pi_{s}}{\pi_{s}+\pi_{c}}$, on the return and volatility spreads between sin stocks and non-sin stocks. Consistently with the behavior of the return spread analyzed in Proposition 4, we observe that when $\beta<0 \wedge \gamma<1$ or $\beta>0 \wedge \gamma>1$, sin stocks are riskier than non-sin stocks (i.e., they exhibit higher standard deviation) and command higher return over most of the dividend share region.

The previous analysis clarifies the impact of dividend payments on the riskiness of sin stocks relative to that of non-sin stocks and the resulting compensation required by investors to hold stocks that are perceived as sinful. However, the motivating evidence above refers to the average returns and standard deviation of sin stocks over a given period of time. Going one step further, we also study the implications of dividend/ethicalness complementarity and risk aversion for the average return and volatility differential between sin and non-sin stocks. To do so, we simulate 5000 trajectories of dividends, each of length 50 years, and we compute the return and standard deviation differentials along these trajectories ${ }^{17}$. The average return and standard deviation differentials are reported

\footnotetext{
${ }^{17}$ More precisely, for any value of simulated dividends $D_{1, t}$ and $D_{2, t}$, we compute the conditional returns and the conditional standard deviation. The unconditional return is computed as the average of
} 
in Table 2. We observe that sin stocks are riskier than non-sin stocks and pay, on average, higher returns than non-sin stocks when (i) dividend and ethicalness are substitutes $(\beta<0)$ and the risk aversion is smaller than 1 , or (ii) when dividend and ethicalness are complements $(\beta>0)$ and the risk aversion is larger than 1 . This result depends on the interplay between risk aversion and dividend/ethicalness complementarity and its implications for the desired marginal rate of substitution between dividends and perceived ethicalness. This mechanism is in the spirit of Statman et al. (2008), who argue that expected returns should be higher when objective risk is high and also when subjective risk is high. In our framework, subjective risk is the risk of receiving large dividends from unethical firms.

Finally, it is worth noting that when $\beta=0$ or $\pi_{c}=\pi_{s}$, we are back to the standard case of power utility over multiple consumption goods, where the perceived ethicalness is irrelevant, and the only important risk component is the diversification risk. In the symmetric economy, the fundamentals of the two stocks are the same and the only thing that matters for expected returns is the payment of dividends, as evident from equation (9). As a result, firms that pay higher divided will have higher (lower) expected returns when $\gamma>1(\gamma<1)$. In this case, the symmetric economy is silent about the impact of ethicalness because the two firms are ex-ante identical. ${ }^{18}$ To distinguish between sin and non-sin stock, we have to inspect the asymmetric economy where sin and nonsin stocks have different fundamentals. The expected growth rate and the standard deviation of dividends are higher for sin stocks than for non-sin stocks. Under power utility of consumption, these discrepancies in fundamentals imply that when agents are more risk averse than log utility, sin stocks are worth more than non-sin stocks and, thus, command lower expected returns. These results imply that a standard model based on diversification risk only (i.e., a model where $\beta=0$ or $\pi_{c}=\pi_{s}$ ) does not provide a realistic

conditional returns. The same applies to the standard deviation.

${ }^{18}$ Formally, in this case we cannot even distinguish between sin and non-sin stocks. 
description of the stock return differential between sin and non-sin stocks. In other words, preferences for ethicalness matter for stock returns.

At this point one may wonder whether the previous results are affected by the relative size of the sin sector. In our framework, a proxy for the size of the sin sector is given by the dividend (consumption) share of the sin sector. By inspection of Figure 1, we see that the shape of the return differential and the standard return differential (i.e., the empirical predictions we test below) does not depend on the dividend share (and thus on the relative size of the sin sector) but only on the preference parameters. This suggests that even a more complicated model with $N$ sectors would generate the same qualitative results as the model depicted above. ${ }^{19}$

\section{Empirical analysis}

\subsection{Empirical approach}

Our prima facie evidence (see Section 2), in line with the existing literature, suggests that sin stocks are characterized by higher return and volatility than non-sin comparable stocks. Our theoretical model generates positive average return and volatility spreads between sin and non-sin stocks under two different preference specifications:

i. Dividends and ethicalness are substitute goods and risk aversion is low (lower than $\log$ utility), and

\footnotetext{
${ }^{19}$ The conditional level of the spread instead depends on the size of the two sectors: The conditional spreads are positive when the dividend share of the sin sector is above a given threshold that depends on the preference parameters (Figure 1). For instance, when $\beta=3$ and ethicalness of the sin sector is small compared to that of the rest of the economy $\left(c_{s}=0.1\right)$, the spreads are positive whenever the dividend share is above $10 \%$. To put things in perspective, Figure 3 shows that the dividend of the sin sector $\left(D_{s}\right)$ is about $20 \%$ of the overall dividend of the sin sector and the non-sin comparable sector $\left(D_{s}+D_{c}\right)$ and lies well within $10 \%$ and $30 \%$. For such levels of the dividend share, our model predicts positive spreads when calibrated with positive $\beta$, risk aversion higher than one, and low ethicalness of the sin sector. In a model with $N$ sectors, the dividend share of the sin sector could potentially be lower than $10 \%$ but our basic economic mechanism, in which we are ultimately interested, would still be at work: The $N$-sector model would generate positive return and volatility spreads for low ethicalness of the sin sector and high complementarity between sin dividends and other dividends (i.e., high $\beta$ ).
} 
ii. Dividends and ethicalness are complementary goods and risk aversion is sufficiently high (higher than log utility).

However, case i. and case ii. have opposite predictions when it comes to conditional moments. More precisely, the conditional return and volatility spread between sin and comparable stocks are decreasing (increasing) in the dividend share of sin companies in case i. (ii.). Therefore, we can distinguish between these two cases by looking at the empirical relation between conditional expected return and volatility spreads and the dividend share of sin companies. To do so, we estimate the following predictive regressions for the return spread over different investment horizons $k$ :

$$
\sum_{j=1}^{k}\left(r_{s, t+j}-r_{c, t+j}\right)=b_{0}+b_{1} d_{s, t}+\mathbf{x}_{t} \mathbf{b}+\varepsilon_{t+k} .
$$

$r_{i, t+j}$ is the one-period return for portfolio $i$ at time $t+j$, where $i \in\{s, c\} . d_{s, t}$ is the current dividend share of sin companies.

In additional tests, we include a vector of control variables $\mathbf{x}_{t}$, such as the three Fama-French factors, the momentum factor, the traded liquidity factor by Pástor and Stambaugh (2003), and the litigation risk differential across the two portfolios. We allow for serial correlation and heteroskedasticity in the error terms using Newey-West standard errors (four lags).

We estimate a similar regression specification for the volatility spread

$$
\sigma_{s, t+k}-\sigma_{c, t+k}=b_{0}+b_{1} d_{s, t}+\mathbf{x}_{t} \mathbf{b}+\varepsilon_{t+k}
$$

where portfolio $i$ 's return volatility is given by the sum of the absolute value of deviations from the unconditional mean return, i.e., $\sigma_{i, t+k}=\sum_{j=0}^{k}\left|r_{i, t+j}-\bar{r}_{i}\right|$ for $i \in\{s, c\}$, in line with Bansal, Fang, and Yaron (2005b). For robustness, we also use a measure based on squared deviations from the unconditional mean return, i.e., $\sigma_{i, t+k}=\sqrt{\sum_{j=0}^{k}\left(r_{i, t+j}-\bar{r}_{i}\right)^{2}}$ 
for $i \in\{s, c\}$.

To recap, our empirical strategy proceeds in two steps. First, we estimate the average return and volatility spreads without conditioning on the sin dividend share. The results point toward a positive unconditional volatility spread and a positive unconditional return spread between sin and non sin companies. Second, we condition on the dividend share quantity by estimating equations (13) and (14). The parameter of interest in this case is $b_{1}$. If the positive unconditional spreads were generated by a preference specification where dividends and ethicalness are substitute goods and investors have low risk aversion (case i.), we would expect to find a negative relation between the dividend share of sin companies and return/volatility spreads, that is $b_{1}<0$. Conversely, if the unconditional spreads were generated by a preference specification where dividends and ethicalness are complementary goods and investors have high risk aversion (case ii.), we would expect $b_{1}>0$.

\subsection{Data}

We consider the universe of U.S. firms traded on NYSE, AMEX, and NASDAQ between 1926 and 2015. We obtain monthly total stock return data from the Center for Research in Security Prices (CRSP) and accounting data from Standard \& Poor's Compustat. We require each firm to have traded ordinary shares (CRSP share code 10 or 11). We also obtain consumer price index (CPI) series from Federal Reserve Economic Data (FRED) of the St. Louis Federal Reserve Bank, risk factors (excess market return, small minus big, high minus low, and momentum) from Kenneth French's website, and the liquidity factor from Robert Stambaugh's website.

Our sin portfolio includes companies producing alcoholic beverages, smoke products, and gaming. In addition, we construct an extended sin portfolio that also includes companies involved in the distribution of sin products. The non-sin comparable portfolio 
include companies operating in the food, soda, fun, and meals industries. The sin portfolio and the extended sin portfolio comprise 235 and 408 companies, respectively. The non-sin comparable portfolio contains 1,943 companies. We compute value-weighted real returns on these portfolios at quarterly frequency. ${ }^{20}$ For robustness, we also compute equally-weighted returns. We provide details on the portfolio construction procedure in Appendix C.

We conduct our baseline analysis over the period 1965Q1:2015Q4. Indeed, it was in 1965, amid growing health concerns about smoking, that the Congress passed the Federal Cigarette Labeling and Advertising Act, which substantially restricted cigarette packaging practices (Hong and Kacperczyk, 2009). This can be seen as a turning point in social norms about smoke products, after which companies operating in that industry can be unambiguously classified as sinful. We also conduct robustness tests using the whole sample period 1926Q3:2015Q4.

Our main variable of interest is the dividend share of sin companies $\left(d_{s}\right)$. We construct our measure of dividend payments at monthly frequency from CRSP adjusting for stock repurchases (Bansal et al., 2005a). We then convert these dividend payments to quarterly frequency by summing monthly payments within each quarter. Moreover, to mitigate seasonal effects, we take the trailing four-quarter average as in Bansal et al. (2005a). Figure 3 shows the evolution of the dividend share of the sin portfolio (top graphs) and of the extended sin portfolio (bottom graphs) through time, both for repurchaseadjusted dividend payments (left graphs) and dividend-only payments (right graphs). For robustness, we also construct Compustat measures of payout following Skinner (2008).

In additional tests, we control for the factors of Fama and French (1993) and Fama and French (2015), the traded liquidity factor of Pástor and Stambaugh (2003), and lit-

\footnotetext{
${ }^{20}$ In line with Bansal, Dittmar, and Lundblad (2005a) and Bansal et al. (2005b), we use data at quarterly frequency, which allows us to better remove seasonal patterns from the time-series of dividend payments.
} 
igation risk differential between the sin and comparable portfolio $(\Delta L I T)$. We compute the litigation risk of each portfolio-quarter as the fraction of non-missing after-tax settlement entries (Compustat item seta) among its constituent companies (Jagannathan and Wang, 1996; Luo and Balvers, 2017). Figure 4 plots $\Delta L I T$ for the sin (top graph) and the extended sin portfolio (bottom graph). While litigation risk is generally higher for sin companies than for comparable companies, we observe several periods in which the reverse holds.

\subsection{Results}

\subsubsection{Unconditional moments}

To test our model's predictions about unconditional moments, we compute the mean return and volatility spreads between the sin and the non-sin comparable portfolio over different investment horizons (one year, two years, and three years) and report the results in Table 3. Line [a] considers our baseline case, namely return and volatility spreads between sin and comparable companies using value-weighted returns over the period 1965Q1:2015Q4. Line [b] relies on equally-weighted returns. Line [c] repeats the analysis using the extended sin portfolio. Line [d] extends the analysis to the whole sample period 1926Q3:2015Q4. Line [e] considers the same case as in line [a] but uses an alternative measure of volatility based on squared deviations from the unconditional mean return. ${ }^{21}$ In each case, as expected, the return and volatility differentials are positive at all horizons. While the return spread is in some instances insignificant (especially at shorter investment horizons for equally-weighted portfolios), the volatility spread is always statistically significant.

The observed positive return and volatility spreads suggest that the empirically relevant preference specifications are indeed $\beta<0 \wedge \gamma<1$ or $\beta>0 \wedge \gamma>1$. Our theory

\footnotetext{
${ }^{21}$ Clearly, the return spread is unaffected by the alternative volatility measure.
} 
appears to capture volatility spreads especially well.

\subsubsection{Conditional moments}

We now study the conditional spreads to distinguish between the two preference specifications that are able to generate the positive average return and volatility spreads within our theoretical framework. Motivated by our model, we regress the return and volatility spreads on the sin portfolio dividend share $d_{s}$. Table 4 estimates equations (13) and (14) at different investment horizons. In Panel A, our baseline case, we consider return and volatility spreads between sin and comparable companies using value-weighted returns and repurchase-adjusted dividend share $d_{s}$ over the period 1965Q1:2015Q4. In Panel $\mathrm{B}$, we use equally-weighted returns. In Panel $\mathrm{C}$, we use the extended sin portfolio. In Panel D, we rely on the whole sample period 1926Q3:2015Q4. In Panel E, we consider the same case as Panel A but use an alternative measure of volatility based on squared deviations from the unconditional mean return. The relations between both the return and the volatility spread and the dividend share of the sin portfolio are invariably positive. Again, we find that the coefficient of $d_{s}$ is always statistically significant for the volatility spread, whereas it is significant for the return spread only in the baseline case (i.e., value-weighted portfolios and dividends adjusted for stock repurchases) and using the extended sin portfolio.

Figure 5 plots the predicted spreads based on the coefficient estimates in Panel A over the empirically relevant range of $d_{s}$. Positive changes in $d_{s}$ are associated with positive and economically large changes in both spreads. ${ }^{22}$ The linear predictions broadly match the patterns of our calibration exercise in Figure 1.

\footnotetext{
${ }^{22}$ The predictive power of the dividend share of sin stocks for the return spread between sin and non-sin stocks is consistent with the recent literature showing that forecasts of the dividends growth rate help predict future stock returns (Lettau and Ludvigson, 2005; Lacerda and Santa-Clara, 2010). Indeed, the current dividend share of sin stocks contains information about the future path of dividends payments which, in turn, determines the future diversification risk and the return spread, depending on the complementarity between dividend and ethicalness and the investors' degree of risk aversion.
} 
Taken together, these results suggest the existence of positive links between both the return and volatility spreads between sin and non-sin stocks, and the dividend share of sin stocks. These positive relations are consistent with a model where dividends and ethicalness are complementary goods, and investors are more risk averse than log. We also note that the interplay between ethical and risk preferences seem to importantly feed back into the volatilities.

Finally, the existing literature is to a large extent silent with respect to the explanation for the conditional returns of sin companies. An exception is Salaber (2009). She tests a conditional model that allows for time-varying risk premia and shows that several macroeconomic variables (such as the default spread, the term spread, and the dividend yield) help explain the return differential between sin and non-sin stocks. In a similar fashion, Liston (2016) shows that the conditional excess returns and the conditional standard deviation of sin stocks are affected by investor sentiment. ${ }^{23}$ In comparison to the existing literature our model progresses the understanding of the conditional properties of the stock returns of sin and non-sin stocks.

Other explanations. Our theoretical model suggests that the relevant state variable to explain the return and standard deviation differential between the sin and the non-sin sector is the dividend share of sin companies. Here we discuss possible alternative explanations.

Table 5 re-estimates equations (13) and (14) controlling for well-known risk factors. Panel A controls for the three Fama-French factors and momentum. Panel B includes also the traded liquidity factor by Pástor and Stambaugh (2003) among the control variables. This liquidity factor is available from 1968Q1. Our baseline results remain

\footnotetext{
${ }^{23}$ There are two important difference in our paper with respect to Liston (2016). First, we analyze the conditional return differential between sin and non-sin stocks rather than the excess return of sin stocks with respect to the risk-free rate. Second, our empirical approach focuses on predictive regressions in the sense that we study the relation between risk factors at time $t$ and returns at time $t+k$, whereas Liston (2016) analyzes the contemporaneous relation between investor sentiment and sin stock returns.
} 
unchanged for both Panel A and Panel B. Note that the momentum factor also proxies for investor sentiment (Stambaugh, Yu, and Yuan, 2012). This reduces the concerns that the return and standard deviation spreads between sin and ethical stocks are driven by investor sentiment. Panel C, in the spirit of Luo and Balvers (2017), controls also for the litigation risk differential between sin and comparable industries $(\Delta L I T)$, which is available from 1996Q1. In this case, $d_{s}$ exhibits a positive and statistically significant coefficient only at shorter investment horizons. By contrast, over longer horizons, $d_{s}$ is at times insignificant. However, the rather short sample period may complicate inference. Finally, Blitz and Fabozzi (2017) suggest that the extra-performance of sin stocks with respect to the market can be explained by the profitability and investment factors of Fama and French (2015). In Panel D, we thus also control for the profitability and investment factors besides the traditional three Fama-French factors. Our results survive also in this case. It is important to note the profitability and investment factors are not statistically significant, which suggests that they affect sin and comparable stocks in the same way and, thus, do not affect their difference.

One may argue that the sin premium simply reflects sin stocks' higher exposure to risk that is not captured by the risk factors above. However, sin goods tend to exhibit a steady demand throughout the business cycle because of their addictive properties (Becker and Murphy, 1988). In Appendix C.3, we analyze the business cycle properties of sin good consumption. We consistently find that, if anything, sin goods are less cyclical than our comparable goods and are substantially less cyclical than durable goods. As a result, sin stocks may allow investors to reduce their exposure to market risk and receive relatively steady cash flows in recessions (i.e., in periods of high marginal utility of consumption). Such a risk channel would thus be difficult to reconcile with a sin premium.

Alternative dividend measures. Table 6 re-estimates equations (13) and (14) using alternative dividend measures to compute the dividend share $d_{s}$. Panel A uses dividends 
alone, i.e., without repurchases (Bansal et al., 2005a). Again, we find a positive and statistically significant association between both the return and volatility spread, and $d_{s}$. Panel B uses payouts from Compustat as defined by Skinner (2008). In this case, we find a positive and statistically significant association between the volatility spread and $d_{s}$ at all horizons. By contrast, for the return spread, the estimated $d_{s}$ coefficient is positive but insignificant.

Moreover, our empirical measure of dividend share $\left(d_{s}=\frac{D_{s}}{D_{s}+D_{c}}\right)$ is expressed in units of consumption of the CPI basket. Using the model notation, this measure can be seen as dividends in terms of numeraire units, namely $p_{i} D_{i}$ for $i \in\{s, c\}$. Therefore, we also construct the time series of relative prices $p_{s}$ and $p_{c}$, and convert each portfolio's payouts into the corresponding consumption streams $\left(D_{s}, D_{c}\right)$. To this end, in the spirit of Ferson and Constantinides (1991), we use the sin (non-sin) components of the CPI to deflate $\sin$ (comparable) companies' payouts. ${ }^{24}$ While the dividend share measure obtained in this way is the closest to the model, it is available only starting in 1986Q1 and arguably noisy. Because of this, with slight abuse of notation, we denote it as $\tilde{d}_{s}$ rather than $d_{s}$. In Panel C of Table 6, we repeat our tests using $\tilde{d}_{s}$ as explanatory variable. The relation between the volatility spread and $\tilde{d}_{s}$ is positive and significant, whereas the relation is positive but insignificant for the return spread.

\section{Conclusion}

In this paper, we propose a preference-based explanation for the return and volatility spread between sin stocks and non-sin stocks. The key factor in our model is the marginal rate of substitution between dividends and ethicalness. When the marginal rate of substitution is positive, investors would like to be compensated for the risk of consuming the "less preferred" dividends (i.e., the sin dividends). Therefore, they require average higher

\footnotetext{
${ }^{24}$ More details on the construction of these two price indices are provided in Appendix C.
} 
returns to hold sin stocks in equilibrium. The positive marginal rate of substitution between dividends and ethicalness can be obtained either in a setting in which dividends and ethicalness are substitutes and investors are less risk averse than the log utility, or in a setting in which dividends and ethicalness are complementary goods and investors are more risk averse than log. However, only by adopting the latter model specification will the return and volatility spreads between sin and non-sin stocks exhibit a positive relation with the dividend share of sin stocks, such as the one we observe in the U.S. data.

Although we focus on the U.S. market, our analysis helps understand how the attitudes of investors toward sin stocks affect prices and returns. Our results also help explain the mixed evidence about the sin premium across countries (Durand et al., 2013; Fauver and McDonald, 2014). While in European and American markets sin stocks tend to pay higher average returns than ethical stocks, in the Asia Pacific countries those differences are largely attenuated and, in some of these countries, sin stocks pay lower risk-adjusted returns even though institutional investors underweight sin stocks (as postulated by the boycott theory). Our model suggests that differences in the degree of substitutability between dividends and ethicalness are capable of reconciling these different results. These considerations call for further theoretical and empirical studies that we leave for future research. 


\section{References}

Albuquerque, R., Y. Koskinen, and C. Zhang. Forthcoming. Corporate Social Responsibility and Firm Risk: Theory and Empirical Evidence. Management Science .

Baker, S., B. Hollifield, and E. Osambela. 2018. Asset Prices and Portfolios with Externalities. Working paper, University of Virginia.

Bansal, R., R. F. Dittmar, and C. T. Lundblad. 2005a. Consumption, Dividends, and the Cross Section of Equity Returns. Journal of Finance 60:1639-1672.

Bansal, R., E. Fang, and A. Yaron. 2005b. Equity Capital: A Puzzle. Working paper, Duke University.

Bansal, R., D. Wu, and A. Yaron. 2016. Socially Responsible Investing: Good Is Good, Bad is Bad. Working paper, Duke University.

Beal, D. J., M. Goyen, and P. Philips. 2005. Why Do We Invest Ethically? Journal of Investing 14:66-78.

Becker, G., and K. Murphy. 1988. A Theory of Rational Addiction. Journal of Political Economy 96:675-700.

Benartzi, S., and R. Thaler. 1995. Myopic Loss Aversion and the Equity Premium Puzzle. Quarterly Journal of Economics 110:73-92.

Bliss, R., and N. Panigirtzoglou. 2004. Option-Implied Risk Aversion Estimates. Journal of Finance 59:407-446.

Blitz, D., and F. Fabozzi. 2017. Sin Stocks Revisited: Resolving the Sin Stock Anomaly. Journal of Portfolio Management pp. 1-7.

Bollen, N. P. B. 2007. Mutual Fund Attributes and Investor Behavior. Journal of Financial and Quantitative Analysis 42:683-708.

Dam, L., and B. J. Heijdra. 2011. The Environmental and Macroeconomic Effects of Socially Responsible Investment. Journal of Economic Dynamics and Control 35:14241434.

Durand, R. B., S. Koh, and P. L. Tan. 2013. The Price of Sin in the Pacific-Basin. Pacific-Basin Finance Journal 21:899-913.

Fabozzi, F. J., K. C. Ma, and B. J. Oliphant. 2008. Sin Stock Returns. Journal of Portfolio Management 35:82-94.

Fama, E. F., and K. R. French. 1993. Common Risk Factors in the Returns on Stocks and Bonds. Journal of Financial Economics 33:3-56.

Fama, E. F., and K. R. French. 1997. Industry Costs of Equity. Journal of Financial Economics 43:153-193.

Fama, E. F., and K. R. French. 2007. Disagreement, Tastes, and Asset Prices. Journal of Financial Economics 83:667-689. 
Fama, E. F., and K. R. French. 2015. A Five-Factor Asset Pricing Model. Journal of Financial Economics 116:1-22.

Fauver, L., and M. B. McDonald. 2014. International Variation in Sin Stocks and Its Effects on Equity Valuation. Journal of Corporate Finance 25:173-187.

Ferson, W. E., and G. M. Constantinides. 1991. Habit Persistence and Durability in Aggregate Consumption: Empirical Tests. Journal of Financial Economics 29:199240.

Frijns, B., E. Koellen, and T. Lehnert. 2008. On the Determinants of Portfolio Choice. Journal of Economic Behavior \& Organization 66:373386.

Gomes, J., L. Kogan, and M. Yogo. 2009. Durability of output and expected stock returns. Journal of Political Economy 117:941-986.

Heinkel, R., A. Kraus, and J. Zechner. 2008. The Effect of Green Investment on Corporate Behavior. Journal of Financial and Quantitative Analysis 36:431-449.

Hong, H., and M. Kacperczyk. 2009. The Price of Sin: The Effects of Social Norms on Markets. Journal of Financial Economics 93:15-36.

Hong, H., and L. Kostovetsky. 2012. Red and Blue Investing: Values and Finance. Journal of Financial Economics 103:1-19.

Jagannathan, R., and Z. Wang. 1996. The Conditional CAPM and the Cross-Section of Expected Returns. Journal of Finance 51:3-53.

Karatzas, I., J. P. Lehoczky, and E. Shreve. 1987. Optimal Portfolio and Consumption Decisions for a Small Investor on a Finite Horizon. SIAM Journal on Control and Optimization 25:1577-1586.

Kitzmueller, M., and J. Shimshack. 2012. Economic Perspectives on Corporate Social Responsibility. Journal of Economic Literature 50:51-84.

Kotchen, M. 2006. Green Markets and Private Provision of Public Goods. Journal of Political Economy 114:816834.

Lacerda, F., and P. Santa-Clara. 2010. Forecasting Dividend Growth to Better Predict Returns. Working paper, Nova School of Business.

Lemieux, P. 2003. Does Vice Pay? National Post, available at http://www.independent. org/newsroom/article.asp?id=795.

Lettau, M., and S. Ludvigson. 2005. Expected Returns and Expected Dividend Growth. Journal of Financial Economics 76:583-626.

Levy, H. 1978. Equilibrium in an Imperfect Market: A Constraint on the Number of Securities in the Portfolios. American Economic Review 68:643-658.

Liston, D. P. 2016. Red and Blue Investing: Values and Finance. Quarterly Review of Economics and Finance 59:63-70.

Lucas, R. E. 1978. Asset Prices in an Exchange Economy. Econometrica 46:1429-1445. 
Luo, A., and R. J. Balvers. 2017. Social Screens and Systematic Boycott Risk. Journal of Financial and Quantitative Analysis 52:365-399.

Malkiel, B. G., and Y. Xu. 2006. Idiosyncratic Risk and Security Returns. Working paper, Princeton University.

Pástor, L., and R. F. Stambaugh. 2003. Liquidity Risk and Expected Stock Returns. Journal of Political Economy 111:642-685.

Pavlova, A., and R. Rigobon. 2007. Asset Prices and Exchange Rates. Review of Financial Studies 20:1139-1180.

Phillips, P. J. 2011. Sin Stocks in Self Managed Superannuation Funds. Australian Accounting, Business and Finance Journal 5:39-51.

Salaber, J. 2007. The Determinants of Sin Stock Returns: Evidence on the European Markets. Working paper, Université Paris-Dauphine.

Salaber, J. 2009. Sin Stock Returns over the Business Cycle. Working paper, Université Paris-Dauphine.

Schmitz, J., and J. Schrader. 2015. Corporate Social Responsibility: A Microeconomnic Review of the Literature. Journal of Economic Surveys 29:27-45.

Skinner, D. J. 2008. The Evolving Relation between Earnings, Dividends, and Stock Repurchases. Journal of Financial Economics 87:582-609.

Stambaugh, R. F., J. Yu, and Y. Yuan. 2012. The Short of It: Investor Sentiment and Anomalies. Journal of Financial Economics 104:288-302.

Statman, M., K. L. Fisher, and D. Anginer. 2008. Affect in a Behavioral Asset Pricing Models. Financial Analyst Journal 64:20-29.

Wallenius, J., J. Dyer, P. Fishburn, R. Steuer, S. Zionts, and K. Deb. 2008. Multiple Criteria Decision Making, Multiattribute Utility Theory: Recent Accomplishments and What Lies Ahead. Management Science 54:1336-1349. 

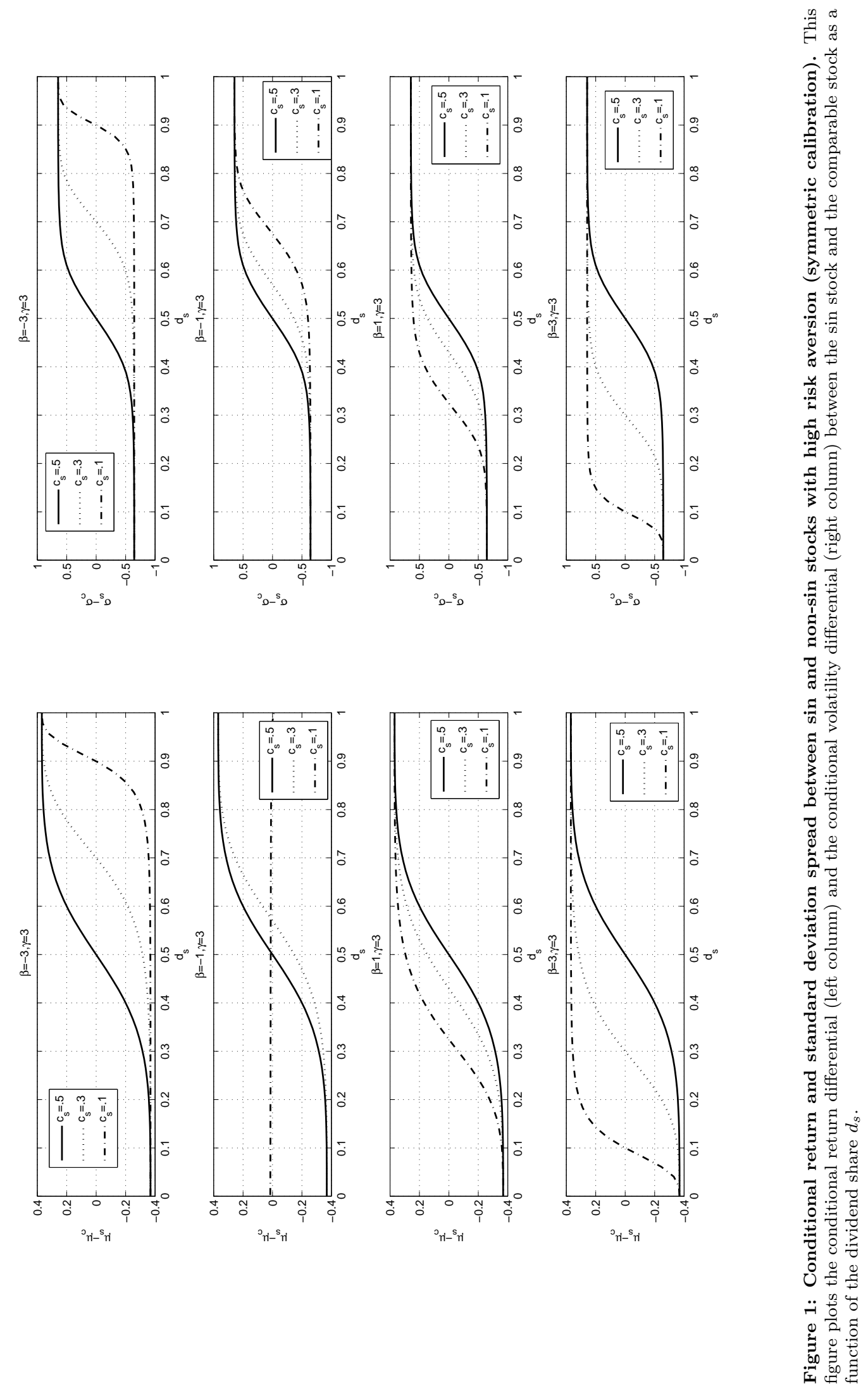

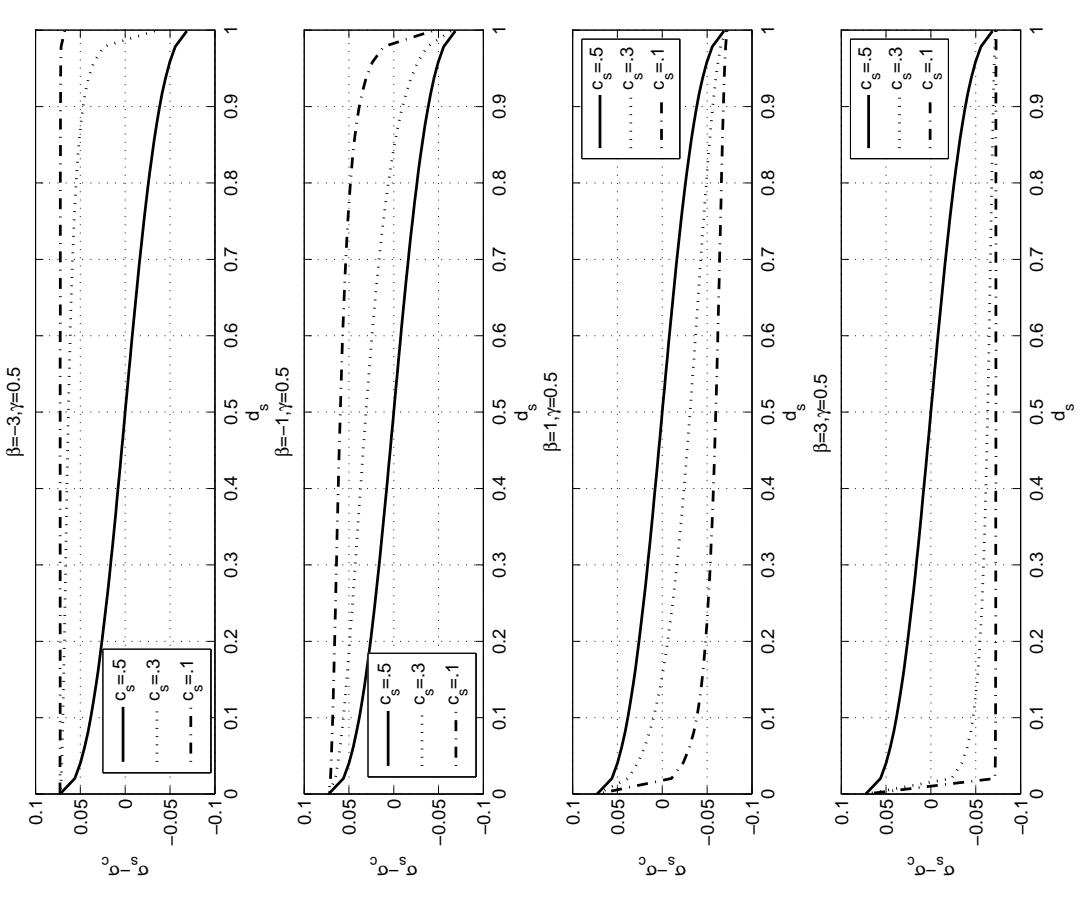

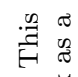
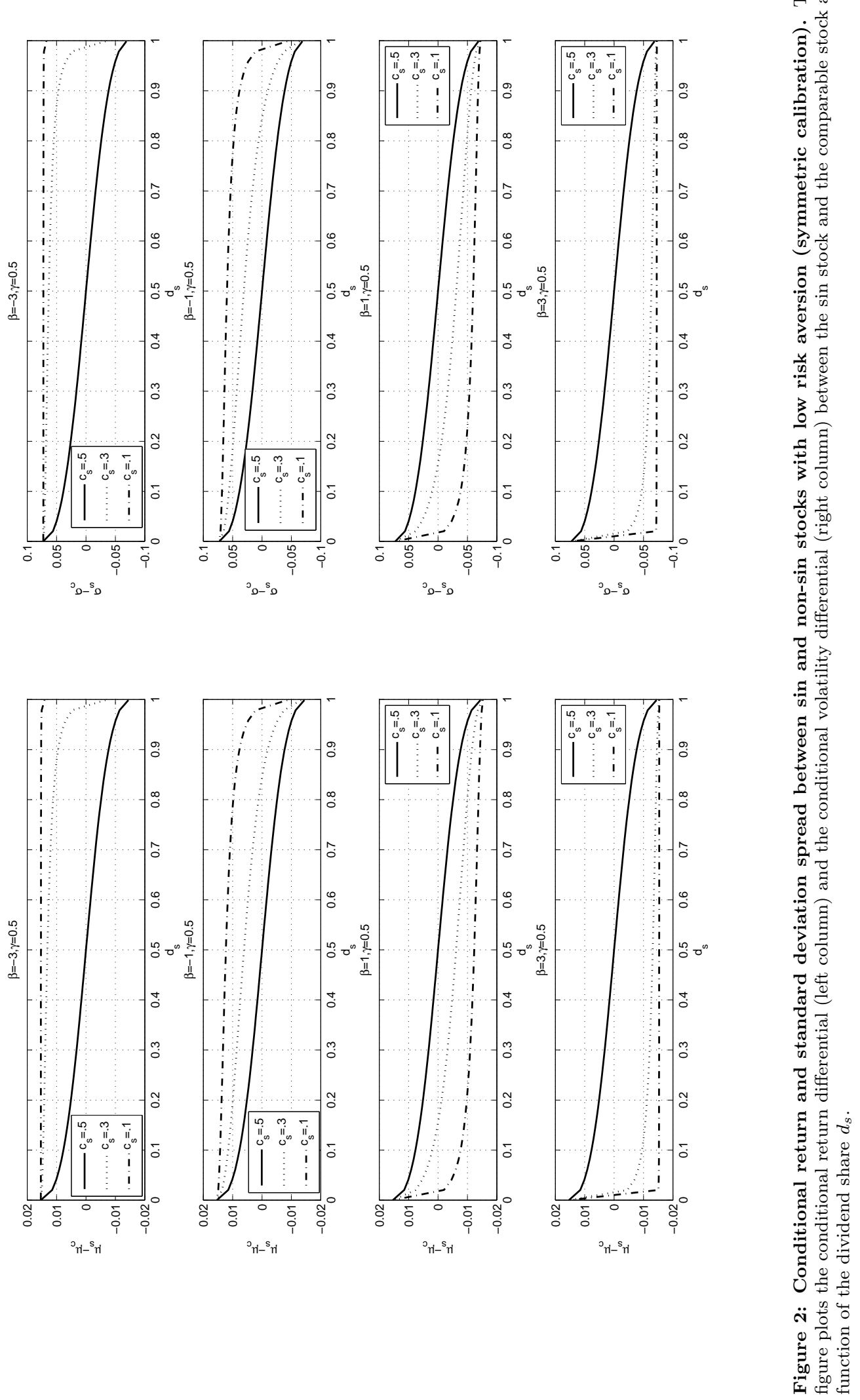

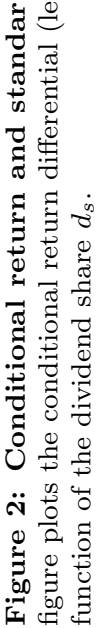



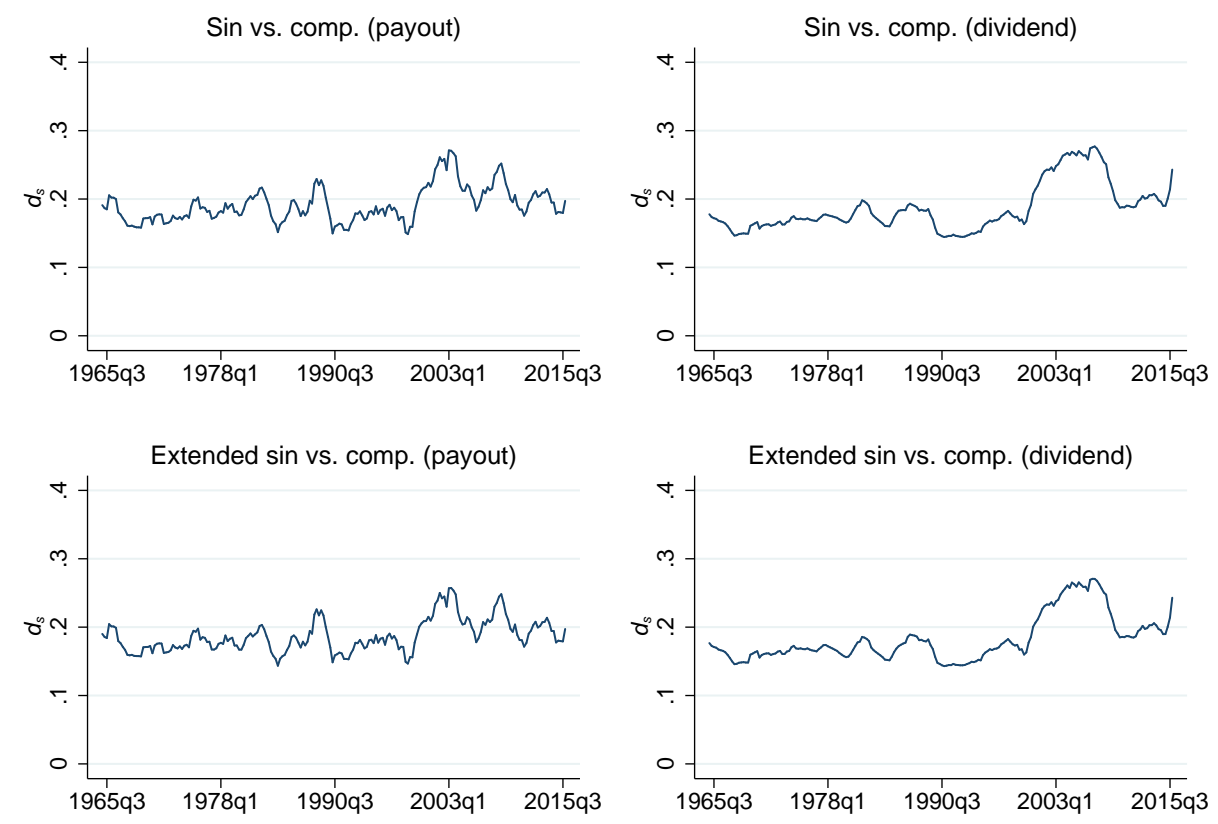

Figure 3: Dividend share of the sin portfolio. This figure plots the evolution of the dividend share of the sin portfolio (top graphs) and of the extended sin portfolio (bottom graphs) through time, both for repurchase-adjusted dividend payments (left graphs) and dividend-only payments (right graphs). 

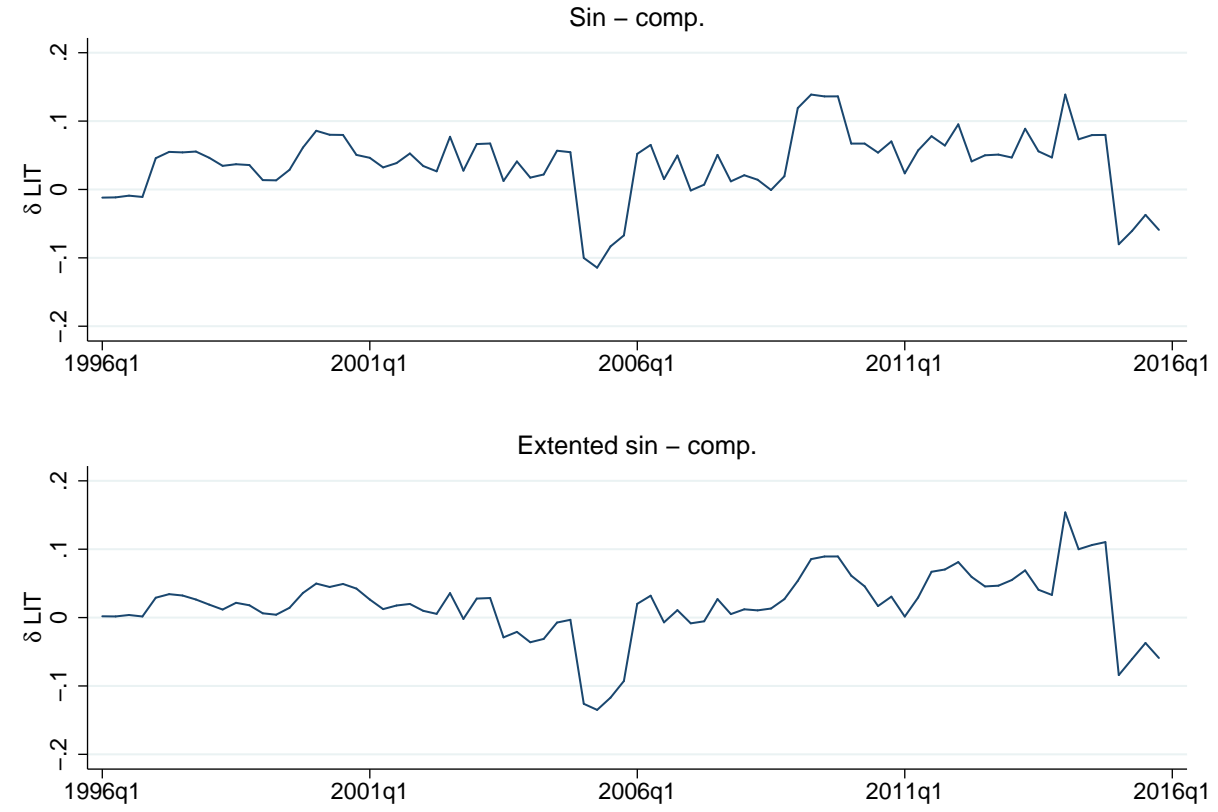

Figure 4: Litigation risk of the sin portfolio. This figure plots the litigation risk differential of the sin (top graph) and the extended sin portfolio (bottom graph) relative to the comparable portfolio $(\Delta L I T)$. 
$1 Y$ return spread

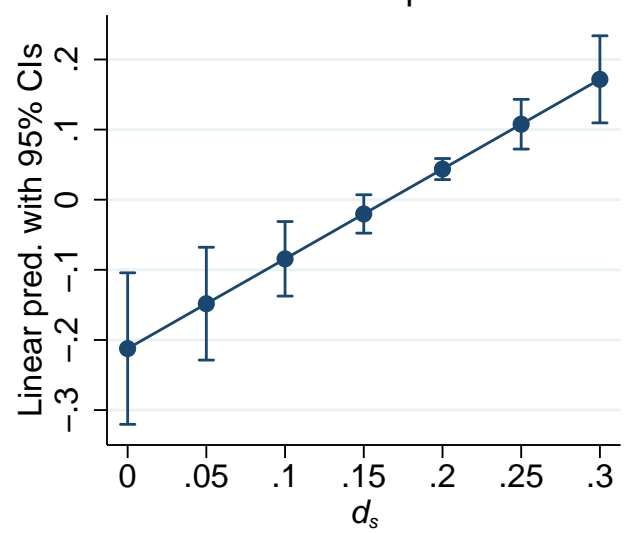

$2 Y$ return spread

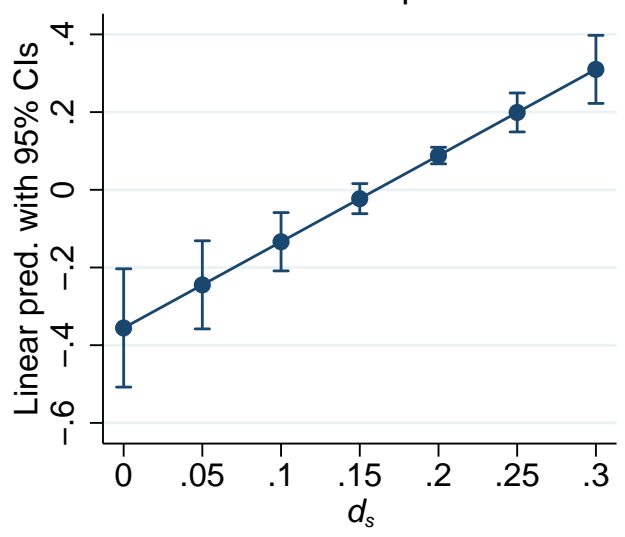

3Y return spread

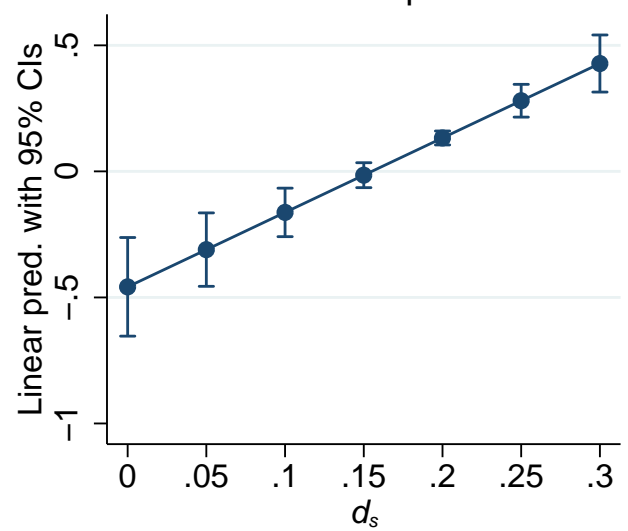

1Y volatility spread

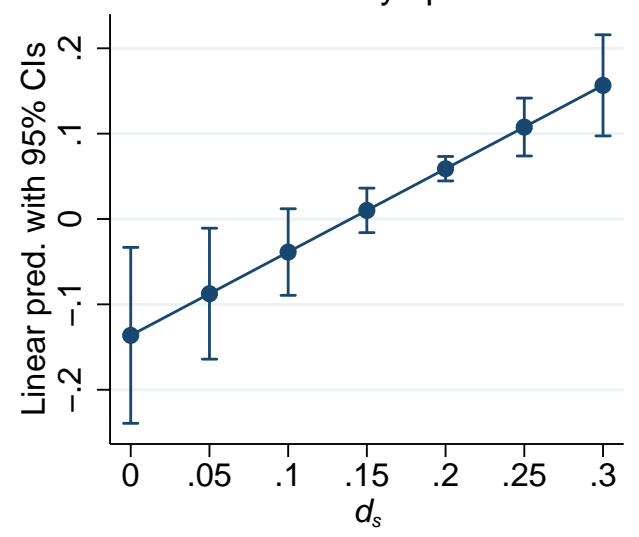

2Y volatility spread

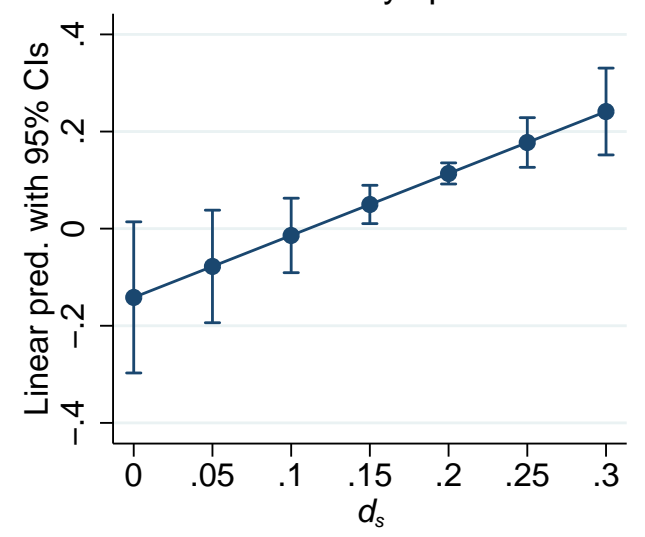

$3 Y$ volatility spread

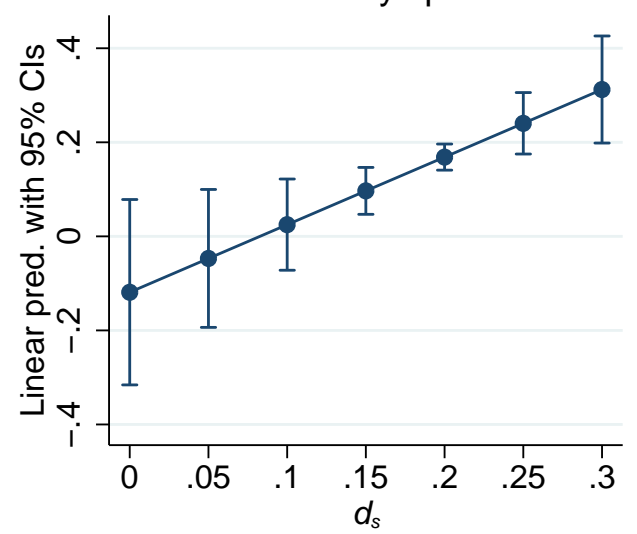

Figure 5: Predicted return and volatility spreads between sin and non-sin stocks. This figure plots the predicted return and volatility spreads between sin and non-sin stocks for given levels of the dividend share of the sin portfolio $d_{s}$. The linear predictions are based on the coefficient estimates of Table 4 (Panel A). 
Table 1: Summary statistics

This table reports summary statistics for three stock portfolios. The sin portfolio includes companies involved in the production of alcoholic beverages, smoke products, and gaming (Panel A). The non-sin comparable portfolio includes companies operating in the food, soda, fun, and meals industries (Panel B). The extended sin portfolio adds to the sin portfolio firms involved in the distribution of sin products (Panel C). Refer to Appendix C.1 for details on portfolio construction. The baseline sample covers U.S. companies from CRSP and Compustat between 1965 and 2015. Value-weigthed (VW) and equally-weighted (EW) portfolio excess returns are reported. Payout yield is computed from repurchase-adjusted dividend payments from CRSP (Bansal et al., 2005a). Dividend yield is computed from dividend-only payments from CRSP. Payout yield (Compustat) is computed from dividend payments and repurchases from Compustat (Skinner, 2008). Litigation risk is available from 1996Q1 and is computed as the fraction of non-missing after-tax settlement entries (Compustat item seta) among the porfolio's constituent companies (Jagannathan and Wang, 1996; Luo and Balvers, 2017). Panel D reports the summary statistics for the dividend share $d_{s}$ of the sin and the extended sin portfolio based both on repurchase-adjusted dividend payments and dividend-only payments. All the variables are at quarterly frequency and are not annualized.

\begin{tabular}{lccc}
\hline Panel A: Sin portfolio & & & \\
\hline & Mean & Std. dev. & Obs. \\
\hline VW excess return & 0.038 & 0.096 & 204 \\
EW excess return & 0.023 & 0.120 & 204 \\
Payout yield & 0.009 & 0.003 & 204 \\
Div. yield & 0.005 & 0.003 & 204 \\
Payout yield (Compustat) & 0.007 & 0.002 & 204 \\
Payout yield (growth rate) & 0.010 & 0.156 & 204 \\
Litigation risk & 0.188 & 0.089 & 80 \\
\hline
\end{tabular}

\begin{tabular}{lccc}
\hline Panel B: Comparable portfolio & & & \\
\hline & Mean & Std. dev. & Obs. \\
\hline VW excess return & 0.029 & 0.086 & 204 \\
EW excess return & 0.017 & 0.112 & 204 \\
Payout yield & 0.008 & 0.002 & 204 \\
Div. yield & 0.004 & 0.002 & 204 \\
Payout yield (Compustat) & 0.006 & 0.002 & 204 \\
Payout yield (growth rate) & 0.006 & 0.098 & 204 \\
Litigation risk & 0.151 & 0.080 & 80 \\
\hline
\end{tabular}

\begin{tabular}{lccc}
\hline Panel C: Extended sin portfolio & & & \\
\hline & Mean & Std. dev. & Obs. \\
\hline VW excess return & 0.038 & 0.094 & 204 \\
EW excess return & 0.018 & 0.121 & 204 \\
Payout yield & 0.008 & 0.003 & 204 \\
Div. yield & 0.004 & 0.002 & 204 \\
Payout yield (Compustat) & 0.006 & 0.002 & 204 \\
Payout yield (growth rate) & 0.008 & 0.144 & 204 \\
Litigation risk & 0.170 & 0.085 & 80 \\
\hline
\end{tabular}

\begin{tabular}{llcr}
\hline Panel D: Cash flow share $\left(d_{s}\right)$ & & & \\
\hline & Mean & Std. dev. & Obs. \\
\hline Payout (sin w.r.t. comp.) & 0.192 & 0.025 & 204 \\
Dividend (sin w.r.t. comp.) & 0.187 & 0.035 & 204 \\
Payout (extended sin w.r.t. comp.) & 0.187 & 0.024 & 204 \\
Dividend (extended sin w.r.t. comp.) & 0.183 & 0.034 & 204 \\
\hline
\end{tabular}


Table 2: Simulated return and volatility spreads

This table reports the simulated average return and volatility spreads between sin and non-sin stocks. The spreads in Panel A are obtained under the assumption that the dividend process of the two portfolios is governed by the same parameters (symmetric calibration). The spreads in Panel B are obtained under the assumption that the dividend process of the two portfolios is governed by different parameters (asymmetric calibration based on Panel D of Table 1). 5000 trajectories of dividends are simulated, each of length 50 years. The return and volatility spreads are computed along these trajectories.

\begin{tabular}{|c|c|c|c|c|}
\hline \multicolumn{5}{|c|}{ Panel A: Symmetric calibration } \\
\hline & \multicolumn{2}{|c|}{$\mu_{s}-\mu_{c}$} & \multicolumn{2}{|c|}{$\sigma_{s}-\sigma_{c}$} \\
\hline & $\begin{array}{c}(1) \\
\gamma=0.5\end{array}$ & $\begin{array}{c}(2) \\
\gamma=3\end{array}$ & $\begin{array}{c}(3) \\
\gamma=0.5\end{array}$ & $\begin{array}{c}(4) \\
\gamma=3\end{array}$ \\
\hline$\beta=-20$ & 0.0153 & -0.3598 & 0.0726 & -0.6316 \\
\hline$\beta=-10$ & 0.0153 & -0.2863 & 0.0724 & -0.5096 \\
\hline$\beta=-3$ & 0.0108 & -0.0949 & 0.0527 & -0.1760 \\
\hline$\beta=-1$ & 0.0039 & -0.0113 & 0.01973 & -0.0211 \\
\hline$\beta=0$ & -0.0005 & 0.0317 & -0.0027 & 0.0595 \\
\hline$\beta=1$ & -0.0049 & 0.0736 & -0.0247 & 0.1373 \\
\hline$\beta=3$ & -0.0113 & 0.1491 & -0.0552 & 0.2734 \\
\hline$\beta=10$ & -0.0153 & 0.3062 & -0.0724 & 0.5433 \\
\hline$\beta=20$ & -0.0153 & 0.3626 & -0.0726 & 0.6362 \\
\hline
\end{tabular}

Panel B: Asymmetric calibration

\begin{tabular}{lcccc}
\hline & \multicolumn{3}{c}{$\mu_{s}-\mu_{c}$} & \multicolumn{2}{c}{$\sigma_{s}-\sigma_{c}$} \\
\cline { 2 - 3 } & $\gamma=0.5$ & $\gamma=3$ & $(2)$ & $(4)$ \\
\cline { 3 - 4 }$\beta=-20$ & 0.0224 & -0.5279 & $\gamma=0.5$ & -0.6647 \\
$\beta=-10$ & 0.0222 & -0.4348 & 0.1208 & -0.5252 \\
$\beta=-3$ & 0.0105 & -0.2000 & 0.1203 & -0.1323 \\
$\beta=-1$ & 0.0012 & -0.1123 & 0.0808 & 0.0293 \\
$\beta=0$ & -0.0025 & -0.0707 & 0.0390 & 0.1058 \\
$\beta=1$ & -0.0053 & -0.03211 & 0.0199 & 0.1763 \\
$\beta=3$ & -0.0083 & 0.0348 & 0.0054 & 0.2970 \\
$\beta=10$ & -0.0095 & 0.1717 & -0.0099 & 0.5409 \\
$\beta=20$ & -0.0096 & 0.2239 & -0.0167 & 0.6328 \\
\hline
\end{tabular}


Table 3: Analysis of unconditional return and volatility spreads

This table reports mean return and volatility spreads between the sin and the non-sin comparable portfolio. Columns 1 through 3 analyze the return spread. Columns 4 through 6 analyze the volatility spread. Columns 1 and 4 show results at the one-year investment horizon. Columns 2 and 5 show results at the two-year investment horizon. Columns 3 and 6 show results at the three-year investment horizon. Case [a] (the baseline) considers value-weighted (VW) returns of the sin portfolio over the period 1965Q1:2015Q4. Case [b] considers equally-weighted (EW) returns. Case [c] considers the extended sin portfolio. Case [d] considers the extended sample period 1926Q3:2015Q4. Case [e] considers the same case as [a] but uses a measure of volatility based on squared deviations from the unconditional mean return. All the variables are at quarterly frequency. The $p$-values are computed using Newey-West standard errors with four lags (in parentheses). Significance at the $10 \%, 5 \%$, and $1 \%$ levels are indicated by ${ }^{*},{ }^{* *},{ }^{* * *}$, respectively. Refer to Appendix C.1 for details on portfolio construction.

\begin{tabular}{|c|c|c|c|c|c|c|}
\hline & \multicolumn{3}{|c|}{$\sum_{j=1}^{k}\left(r_{s, t+j}-r_{c, t+j}\right)$} & \multicolumn{3}{|c|}{$\sigma_{s, t+k}-\sigma_{c, t+k}$} \\
\hline & $k \stackrel{(1)}{=1 \mathrm{Y}}$ & $\begin{array}{c}(2) \\
k=2 \mathrm{Y}\end{array}$ & $\begin{array}{c}(3) \\
k=3 \mathrm{Y}\end{array}$ & $\begin{array}{c}(4) \\
k=1 \mathrm{Y}\end{array}$ & $\begin{array}{c}(5) \\
k=2 \mathrm{Y}\end{array}$ & $\begin{array}{c}(6) \\
k=3 \mathrm{Y}\end{array}$ \\
\hline [a] VW & $\begin{array}{c}0.033^{* *} \\
(0.010)\end{array}$ & $\begin{array}{c}0.070^{* * *} \\
(0.002)\end{array}$ & $\begin{array}{c}0.107^{* * *} \\
(0.000)\end{array}$ & $\begin{array}{c}0.051^{* * *} \\
(0.000)\end{array}$ & $\begin{array}{c}0.103^{* * *} \\
(0.000)\end{array}$ & $\begin{array}{c}0.156^{* * *} \\
(0.000)\end{array}$ \\
\hline [b] EW & $\begin{array}{c}0.020 \\
(0.165)\end{array}$ & $\begin{array}{l}0.043^{*} \\
(0.087)\end{array}$ & $\begin{array}{c}0.069^{* *} \\
(0.042)\end{array}$ & $\begin{array}{l}0.026^{*} \\
(0.072)\end{array}$ & $\begin{array}{c}0.054^{* *} \\
(0.042)\end{array}$ & $\begin{array}{r}0.082^{* *} \\
(0.027)\end{array}$ \\
\hline [c] VW (extended) & $\begin{array}{c}0.030^{* * *} \\
(0.007)\end{array}$ & $\begin{array}{c}0.064^{* * *} \\
(0.001)\end{array}$ & $\begin{array}{c}0.098^{* * *} \\
(0.000)\end{array}$ & $\begin{array}{c}0.043^{* * *} \\
(0.000)\end{array}$ & $\begin{array}{c}0.088^{* * *} \\
(0.000)\end{array}$ & $\begin{array}{c}0.133^{* * *} \\
(0.000)\end{array}$ \\
\hline [d] VW (1926Q3:2015Q4) & $\begin{array}{c}0.012 \\
(0.323)\end{array}$ & $\begin{array}{c}0.027 \\
(0.182)\end{array}$ & $\begin{array}{l}0.047^{*} \\
(0.068)\end{array}$ & $\begin{array}{c}0.041^{* * *} \\
(0.000)\end{array}$ & $\begin{array}{c}0.081^{* * *} \\
(0.000)\end{array}$ & $\begin{array}{c}0.120^{* * * *} \\
(0.000)\end{array}$ \\
\hline [e] VW (alt. volatility) & $\begin{array}{c}0.033^{* *} \\
0.010\end{array}$ & $\begin{array}{c}0.070^{* * *} \\
0.002\end{array}$ & $\begin{array}{c}0.107^{* * *} \\
0.000\end{array}$ & $\begin{array}{c}0.025^{* * *} \\
0.000\end{array}$ & $\begin{array}{c}0.033^{* * *} \\
0.000\end{array}$ & $\begin{array}{c}0.038^{* * *} \\
0.000\end{array}$ \\
\hline
\end{tabular}


Table 4: Analysis of conditional return and volatility spreads

This table reports estimates from regressions of return and volatility spreads between the sin and the non-sin comparable portfolio on the dividend share of the sin portfolio $d_{s} . d_{s}$ is computed from repurchase-adjusted dividend payments from CRSP (Bansal et al., 2005a). Columns 1 through 3 analyze the return spread. Columns 4 through 6 analyze the volatility spread. Columns 1 and 4 show results at the one-year investment horizon. Columns 2 and 5 show results at the two-year investment horizon. Columns 3 and 6 show results at the three-year investment horizon. Panel A (the baseline) considers value-weighted (VW) returns of the sin portfolio over the period 1965Q1:2015Q4. Panel B considers equally-weighted (EW) returns. Panel C considers the extended sin portfolio. Panel D considers the extended sample period 1926Q3:2015Q4. Panel E considers the same case as Panel A but uses an alternative measure of volatility based on squared deviations from the unconditional mean return. All the variables are at quarterly frequency. The $t$-statistics (in parentheses) are computed computed using Newey-West standard errors with four lags. Significance at the 10\%, $5 \%$, and $1 \%$ levels are indicated by ${ }^{*},{ }^{* *},{ }^{* *}$, respectively. Refer to Appendix C.1 for details on portfolio construction.

\begin{tabular}{|c|c|c|c|c|c|c|}
\hline \multicolumn{7}{|c|}{ Panel A: VW } \\
\hline & \multicolumn{3}{|c|}{$\sum_{j=1}^{k}\left(r_{s, t+j}-r_{c, t+j}\right)$} & \multicolumn{3}{|c|}{$\sigma_{s, t+k}-\sigma_{c, t+k}$} \\
\hline & $\begin{array}{c}(1) \\
k=1 \mathrm{Y}\end{array}$ & $\begin{array}{c}(2) \\
k=2 \mathrm{Y}\end{array}$ & $\begin{array}{c}(3) \\
k=3 \mathrm{Y}\end{array}$ & $\begin{array}{c}(4) \\
k=1 \mathrm{Y}\end{array}$ & $\begin{array}{c}(5) \\
k=2 \mathrm{Y}\end{array}$ & $\begin{array}{c}(6) \\
k=3 \mathrm{Y}\end{array}$ \\
\hline Constant & $\begin{array}{c}-0.212^{* * *} \\
(-2.83)\end{array}$ & $\begin{array}{c}-0.356^{* * *} \\
(-3.22)\end{array}$ & $\begin{array}{c}-0.458^{* * *} \\
(-2.78)\end{array}$ & $\begin{array}{r}-0.136^{*} \\
(-1.75)\end{array}$ & $\begin{array}{l}-0.142 \\
(-1.17)\end{array}$ & $\begin{array}{l}-0.119 \\
(-0.74)\end{array}$ \\
\hline$d_{s, t}$ & $\begin{array}{c}1.280^{* * *} \\
(3.12)\end{array}$ & $\begin{array}{c}2.219^{* * *} \\
(3.92)\end{array}$ & $\begin{array}{c}2.953^{* * *} \\
(3.59)\end{array}$ & $\begin{array}{c}0.976^{* *} \\
(2.39)\end{array}$ & $\begin{array}{c}1.276^{* *} \\
(2.11)\end{array}$ & $\begin{array}{l}1.437^{*} \\
(1.84)\end{array}$ \\
\hline $\begin{array}{l}\text { Observations } \\
\bar{R}^{2}\end{array}$ & $\begin{array}{l}200 \\
0.09\end{array}$ & 196 & 192 & 201 & 197 & 193 \\
\hline
\end{tabular}

\begin{tabular}{|c|c|c|c|c|c|c|}
\hline \multicolumn{7}{|l|}{ Panel B: EW } \\
\hline & \multicolumn{3}{|c|}{$\sum_{j=1}^{k}\left(r_{s, t+j}-r_{c, t+j}\right)$} & \multicolumn{3}{|c|}{$\sigma_{s, t+k}-\sigma_{c, t+k}$} \\
\hline & $\begin{array}{c}(1) \\
k=1 \mathrm{Y}\end{array}$ & $\begin{array}{c}(2) \\
k=2 \mathrm{Y}\end{array}$ & $\begin{array}{c}(3) \\
k=3 \mathrm{Y}\end{array}$ & $\begin{array}{c}(4) \\
k=1 \mathrm{Y}\end{array}$ & $\begin{array}{c}(5) \\
k=2 \mathrm{Y}\end{array}$ & $\begin{array}{c}(6) \\
k=3 \mathrm{Y}\end{array}$ \\
\hline Constant & $\begin{array}{l}-0.060 \\
(-0.56)\end{array}$ & $\begin{array}{l}-0.067 \\
(-0.32)\end{array}$ & $\begin{array}{l}-0.144 \\
(-0.54)\end{array}$ & $\begin{array}{l}-0.188 \\
(-1.61)\end{array}$ & $\begin{array}{r}-0.356^{*} \\
(-1.97)\end{array}$ & $\begin{array}{r}-0.475^{*} \\
(-1.96)\end{array}$ \\
\hline$d_{s, t}$ & $\begin{array}{l}0.415 \\
(0.74)\end{array}$ & $\begin{array}{l}0.574 \\
(0.54)\end{array}$ & $\begin{array}{l}1.111 \\
(0.81)\end{array}$ & $\begin{array}{c}1.117^{*} \\
(1.84)\end{array}$ & $\begin{array}{c}2.136^{* *} \\
(2.35)\end{array}$ & $\begin{array}{c}2.908^{* *} \\
(2.46)\end{array}$ \\
\hline Observations & 200 & 196 & 192 & 201 & 197 & 193 \\
\hline $\bar{R}^{2}$ & 0.00 & 0.00 & 0.01 & 0.06 & 0.09 & 0.10 \\
\hline
\end{tabular}

\begin{tabular}{|c|c|c|c|c|c|c|}
\hline \multicolumn{7}{|c|}{ Panel C: VW (extended) } \\
\hline & \multicolumn{3}{|c|}{$\sum_{j=1}^{k}\left(r_{s, t+j}-r_{c, t+j}\right)$} & \multicolumn{3}{|c|}{$\sigma_{s, t+k}-\sigma_{c, t+k}$} \\
\hline & $\begin{array}{c}(1) \\
k=1 \mathrm{Y}\end{array}$ & $\begin{array}{c}(2) \\
k=2 \mathrm{Y}\end{array}$ & $\begin{array}{c}(3) \\
k=3 \mathrm{Y}\end{array}$ & $\begin{array}{c}(4) \\
k=1 \mathrm{Y}\end{array}$ & $\begin{array}{c}(5) \\
k=2 \mathrm{Y}\end{array}$ & $\begin{array}{c}(6) \\
k=3 \mathrm{Y}\end{array}$ \\
\hline Constant & $\begin{array}{c}-0.167^{* *} \\
(-2.48)\end{array}$ & $\begin{array}{c}-0.304^{* * *} \\
(-3.06)\end{array}$ & $\begin{array}{c}-0.394^{* * *} \\
(-2.64)\end{array}$ & $\begin{array}{l}-0.124 \\
(-1.55)\end{array}$ & $\begin{array}{l}-0.141 \\
(-1.20)\end{array}$ & $\begin{array}{l}-0.123 \\
(-0.83)\end{array}$ \\
\hline$d_{s, t}$ & $\begin{array}{c}1.057^{* * *} \\
(2.79)\end{array}$ & $\begin{array}{c}1.965^{* * *} \\
(3.75)\end{array}$ & $\begin{array}{c}2.636^{* * *} \\
(3.44)\end{array}$ & $\begin{array}{c}0.896^{* *} \\
(2.07)\end{array}$ & $\begin{array}{l}1.224^{*} \\
(1.96)\end{array}$ & $\begin{array}{l}1.373^{*} \\
(1.77)\end{array}$ \\
\hline Observations & 200 & 196 & 192 & 201 & 197 & 193 \\
\hline $\bar{R}^{2}$ & 0.07 & 0.12 & 0.13 & 0.06 & 0.05 & 0.04 \\
\hline
\end{tabular}


Table 4: - Continued

\begin{tabular}{|c|c|c|c|c|c|c|}
\hline \multicolumn{7}{|c|}{ Panel D: VW (1926Q3:2015Q4) } \\
\hline & \multicolumn{3}{|c|}{$\sum_{j=1}^{k}\left(r_{s, t+j}-r_{c, t+j}\right)$} & \multicolumn{3}{|c|}{$\sigma_{s, t+k}-\sigma_{c, t+k}$} \\
\hline & $k \stackrel{(1)}{=1 \mathrm{Y}}$ & $\begin{array}{c}(2) \\
k=2 \mathrm{Y}\end{array}$ & $\begin{array}{c}(3) \\
k=3 \mathrm{Y}\end{array}$ & $\begin{array}{c}(4) \\
k=1 \mathrm{Y}\end{array}$ & $\begin{array}{c}(5) \\
k=2 \mathrm{Y}\end{array}$ & $\begin{array}{c}(6) \\
k=3 \mathrm{Y}\end{array}$ \\
\hline Constant & $\begin{array}{l}-0.048 \\
(-0.82)\end{array}$ & $\begin{array}{l}-0.081 \\
(-0.86)\end{array}$ & $\begin{array}{l}-0.094 \\
(-0.77)\end{array}$ & $\begin{array}{l}-0.039 \\
(-1.02)\end{array}$ & $\begin{array}{l}-0.059 \\
(-0.90)\end{array}$ & $\begin{array}{l}-0.076 \\
(-0.90)\end{array}$ \\
\hline$d_{s, t}$ & $\begin{array}{l}0.385 \\
(1.15)\end{array}$ & $\begin{array}{l}0.717 \\
(1.33)\end{array}$ & $\begin{array}{l}0.924 \\
(1.30)\end{array}$ & $\begin{array}{c}0.496^{* *} \\
(2.26)\end{array}$ & $\begin{array}{c}0.875^{* *} \\
(2.34)\end{array}$ & $\begin{array}{c}1.241^{* * *} \\
(2.63)\end{array}$ \\
\hline $\begin{array}{l}\text { Observations } \\
\bar{R}^{2}\end{array}$ & 351 & 347 & 343 & 352 & 348 & 344 \\
\hline 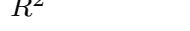 & 0.02 & 0.03 & 0.03 & 0.04 & 0.06 & 0.07 \\
\hline
\end{tabular}

\begin{tabular}{|c|c|c|c|c|c|c|}
\hline \multicolumn{7}{|c|}{ Panel E: VW (alternative volatility measure) } \\
\hline & \multicolumn{3}{|c|}{$\sum_{j=1}^{k}\left(r_{s, t+j}-r_{c, t+j}\right)$} & \multicolumn{3}{|c|}{$\sigma_{s, t+k}-\sigma_{c, t+k}$} \\
\hline & $k \stackrel{(1)}{=1 \mathrm{Y}}$ & $\begin{array}{c}(2) \\
k=2 \mathrm{Y}\end{array}$ & $\begin{array}{c}(3) \\
k=3 \mathrm{Y}\end{array}$ & $\begin{array}{c}(4) \\
k=1 \mathrm{Y}\end{array}$ & $\begin{array}{c}(5) \\
k=2 \mathrm{Y}\end{array}$ & $\begin{array}{c}(6) \\
k=3 \mathrm{Y}\end{array}$ \\
\hline Constant & $\begin{array}{c}-0.212^{* * *} \\
(-2.83)\end{array}$ & $\begin{array}{c}-0.356^{* * *} \\
(-3.22)\end{array}$ & $\begin{array}{c}-0.458^{* * *} \\
(-2.78)\end{array}$ & $\begin{array}{c}-0.098^{* *} \\
(-2.22)\end{array}$ & $\begin{array}{c}-0.121^{* *} \\
(-2.46)\end{array}$ & $\begin{array}{c}-0.134^{* *} \\
(-2.39)\end{array}$ \\
\hline$d_{s}$ & $\begin{array}{c}1.280^{* * *} \\
(3.12)\end{array}$ & $\begin{array}{c}2.219^{* * *} \\
(3.92)\end{array}$ & $\begin{array}{c}2.953^{* * *} \\
(3.59)\end{array}$ & $\begin{array}{c}0.640^{* * *} \\
(2.74)\end{array}$ & $\begin{array}{c}0.802^{* * *} \\
(3.26)\end{array}$ & $\begin{array}{c}0.898^{* * *} \\
(3.28)\end{array}$ \\
\hline Observations & 200 & 196 & 192 & 201 & 197 & 193 \\
\hline $\bar{R}^{2}$ & 0.09 & 0.13 & 0.14 & 0.08 & 0.12 & 0.14 \\
\hline
\end{tabular}


Table 5: Analysis of conditional return and volatility spreads (alternative explanations)

This table reports estimates from regressions of return and volatility spreads between the sin and the non-sin comparable portfolio on the dividend share of the sin portfolio $d_{s}$, controlling for several risk factors. $d_{s}$ is computed from repurchaseadjusted dividend payments from CRSP (Bansal et al., 2005a). Columns 1 through 3 analyze the return spread. Columns 4 through 6 analyze the volatility spread. Columns 1 and 4 show results at the one-year investment horizon. Columns 2 and 5 show results at the two-year investment horizon. Columns 3 and 6 show results at the three-year investment horizon. Regression specifications in Panel A include the following risk factors as control variables (sample period 1965Q1:2015Q4): Excess market return $\left(R_{m}-R_{f}\right)$, small minus big $(S M B)$, high minus low $(H M L)$, and momentum $(U M D)$. Regression specifications in Panel B control for the Pástor and Stambaugh (2003) traded liquidity factor (LIQ), which is available from 1968Q1. Regression specifications in Panel C control for the litigation risk differential between the sin and the non-sin comparable portfolio $(\Delta L I T)$, which is available from 1996Q1. Regression specifications in Panel D controls for the profitability $(R M W)$ and investment $(C M A)$ factors proposed by Fama and French (2015), together with the three traditional factors $R_{m}-R_{f}, S M B$, and $S M L$. Portfolio returns are value-weighted. All the variables are at quarterly frequency. The $t$-statistics (in parentheses) are computed computed using Newey-West standard errors with four lags. Significance at the $10 \%, 5 \%$, and $1 \%$ levels are indicated by ${ }^{*},{ }^{* *},{ }^{* *}$, respectively. Refer to Appendix C.1 for details on portfolio construction.

\begin{tabular}{|c|c|c|c|c|c|c|}
\hline & \multicolumn{3}{|c|}{$\sum_{j=1}^{k}\left(r_{s, t+j}-r_{c, t+j}\right)$} & \multicolumn{3}{|c|}{$\sigma_{s, t+k}-\sigma_{c, t+k}$} \\
\hline & $k \stackrel{(1)}{=} 1 \mathrm{Y}$ & $\begin{array}{l}(2) \\
k=2 \mathrm{Y}\end{array}$ & $\begin{array}{c}(3) \\
k=3 \mathrm{Y}\end{array}$ & $\begin{array}{c}(4) \\
k=1 \mathrm{Y}\end{array}$ & $\begin{array}{c}(5) \\
k=2 \mathrm{Y}\end{array}$ & $\begin{array}{c}(6) \\
k=3 \mathrm{Y}\end{array}$ \\
\hline Constant & $\begin{array}{c}-0.183^{* *} \\
(-2.31)\end{array}$ & $\begin{array}{c}-0.327^{* * *} \\
(-2.90)\end{array}$ & $\begin{array}{c}-0.424^{* * *} \\
(-2.61)\end{array}$ & $\begin{array}{c}-0.129^{*} \\
(-1.71)\end{array}$ & $\begin{array}{l}-0.150 \\
(-1.33)\end{array}$ & $\begin{array}{l}-0.141 \\
(-0.94)\end{array}$ \\
\hline$d_{s, t}$ & $\begin{array}{c}1.147^{* * *} \\
(2.69)\end{array}$ & $\begin{array}{c}2.106^{* * *} \\
(3.66)\end{array}$ & $\begin{array}{c}2.801^{* * *} \\
(3.47)\end{array}$ & $\begin{array}{c}0.963^{* *} \\
(2.46)\end{array}$ & $\begin{array}{c}1.367^{* *} \\
(2.43)\end{array}$ & $\begin{array}{c}1.611^{* *} \\
(2.19)\end{array}$ \\
\hline$R_{m, t}-R_{f, t}$ & $\begin{array}{c}-0.210^{* *} \\
(-2.30)\end{array}$ & $\begin{array}{c}-0.247^{*} \\
(-1.93)\end{array}$ & $\begin{array}{l}-0.272 \\
(-1.38)\end{array}$ & $\begin{array}{l}-0.015 \\
(-0.14)\end{array}$ & $\begin{array}{l}0.095 \\
(0.62)\end{array}$ & $\begin{array}{l}0.196 \\
(1.17)\end{array}$ \\
\hline$S M L_{t}$ & $\begin{array}{c}0.300^{*} \\
(1.82)\end{array}$ & $\begin{array}{l}0.256 \\
(0.99)\end{array}$ & $\begin{array}{l}0.356 \\
(0.91)\end{array}$ & $\begin{array}{l}0.062 \\
(0.36)\end{array}$ & $\begin{array}{l}-0.188 \\
(-0.72)\end{array}$ & $\begin{array}{l}-0.483 \\
(-1.22)\end{array}$ \\
\hline$H M L_{t}$ & $\begin{array}{l}-0.134 \\
(-1.06)\end{array}$ & $\begin{array}{l}-0.338 \\
(-1.47)\end{array}$ & $\begin{array}{l}-0.282 \\
(-0.96)\end{array}$ & $\begin{array}{c}-0.330^{* * *} \\
(-2.64)\end{array}$ & $\begin{array}{c}-0.562^{* *} \\
(-2.49)\end{array}$ & $\begin{array}{l}-0.401 \\
(-1.53)\end{array}$ \\
\hline$U M D_{t}$ & $\begin{array}{l}-0.074 \\
(-0.49)\end{array}$ & $\begin{array}{l}-0.087 \\
(-0.52)\end{array}$ & $\begin{array}{l}-0.035 \\
(-0.18)\end{array}$ & $\begin{array}{l}-0.089 \\
(-0.76)\end{array}$ & $\begin{array}{l}-0.136 \\
(-0.96)\end{array}$ & $\begin{array}{l}-0.242 \\
(-1.52)\end{array}$ \\
\hline $\begin{array}{l}\text { Observations } \\
\bar{R}^{2}\end{array}$ & $\begin{array}{l}200 \\
0.10\end{array}$ & $\begin{array}{l}196 \\
0.14\end{array}$ & $\begin{array}{l}192 \\
0.14\end{array}$ & $\begin{array}{l}201 \\
0.08\end{array}$ & $\begin{array}{l}197 \\
0.08\end{array}$ & $\begin{array}{l}193 \\
0.05\end{array}$ \\
\hline
\end{tabular}

\begin{tabular}{|c|c|c|c|c|c|c|}
\hline \multicolumn{7}{|c|}{ Panel B: Liquidity factor } \\
\hline & \multicolumn{3}{|c|}{$\sum_{j=1}^{k}\left(r_{s, t+j}-r_{c, t+j}\right)$} & \multicolumn{3}{|c|}{$\sigma_{s, t+k}-\sigma_{c, t+k}$} \\
\hline & $\begin{array}{c}(1) \\
k=1 \mathrm{Y}\end{array}$ & $\begin{array}{c}(2) \\
k=2 \mathrm{Y}\end{array}$ & $\begin{array}{c}(3) \\
k=3 \mathrm{Y}\end{array}$ & $\begin{array}{c}(4) \\
k=1 \mathrm{Y}\end{array}$ & $\begin{array}{c}(5) \\
k=2 \mathrm{Y}\end{array}$ & $\begin{array}{c}(6) \\
k=3 \mathrm{Y}\end{array}$ \\
\hline Constant & $\begin{array}{c}-0.198^{* *} \\
(-2.58)\end{array}$ & $\begin{array}{c}-0.343^{* * *} \\
(-3.04)\end{array}$ & $\begin{array}{c}-0.450^{* * *} \\
(-2.87)\end{array}$ & $\begin{array}{l}-0.113 \\
(-1.54)\end{array}$ & $\begin{array}{l}-0.147 \\
(-1.29)\end{array}$ & $\begin{array}{l}-0.122 \\
(-0.79)\end{array}$ \\
\hline$d_{s, t}$ & $\begin{array}{c}1.226^{* * *} \\
(2.94)\end{array}$ & $\begin{array}{c}2.185^{* * *} \\
(3.83)\end{array}$ & $\begin{array}{c}2.898^{* * *} \\
(3.73)\end{array}$ & $\begin{array}{c}0.916^{* *} \\
(2.42)\end{array}$ & $\begin{array}{c}1.403^{* *} \\
(2.48)\end{array}$ & $\begin{array}{c}1.546^{* *} \\
(2.06)\end{array}$ \\
\hline$R_{m, t}-R_{f, t}$ & $\begin{array}{c}-0.219^{* *} \\
(-2.33)\end{array}$ & $\begin{array}{c}-0.251^{*} \\
(-1.92)\end{array}$ & $\begin{array}{l}-0.258 \\
(-1.29)\end{array}$ & $\begin{array}{l}-0.045 \\
(-0.42)\end{array}$ & $\begin{array}{l}0.055 \\
(0.37)\end{array}$ & $\begin{array}{l}0.163 \\
(0.95)\end{array}$ \\
\hline$S M L_{t}$ & $\begin{array}{l}0.296 \\
(1.65)\end{array}$ & $\begin{array}{l}0.258 \\
(0.91)\end{array}$ & $\begin{array}{l}0.241 \\
(0.58)\end{array}$ & $\begin{array}{l}0.154 \\
(0.80)\end{array}$ & $\begin{array}{l}-0.143 \\
(-0.50)\end{array}$ & $\begin{array}{l}-0.402 \\
(-0.94)\end{array}$ \\
\hline$H M L_{t}$ & $\begin{array}{l}-0.115 \\
(-0.92)\end{array}$ & $\begin{array}{l}-0.315 \\
(-1.36)\end{array}$ & $\begin{array}{l}-0.254 \\
(-0.85)\end{array}$ & $\begin{array}{c}-0.355^{* * *} \\
(-2.82)\end{array}$ & $\begin{array}{c}-0.601^{* * *} \\
(-2.61)\end{array}$ & $\begin{array}{l}-0.425 \\
(-1.61)\end{array}$ \\
\hline$U M D_{t}$ & $\begin{array}{l}-0.062 \\
(-0.38)\end{array}$ & $\begin{array}{l}-0.062 \\
(-0.34)\end{array}$ & $\begin{array}{l}-0.041 \\
(-0.20)\end{array}$ & $\begin{array}{l}-0.090 \\
(-0.69)\end{array}$ & $\begin{array}{l}-0.158 \\
(-1.06)\end{array}$ & $\begin{array}{l}-0.223 \\
(-1.32)\end{array}$ \\
\hline$L I Q_{t}$ & $\begin{array}{l}0.060 \\
(0.68)\end{array}$ & $\begin{array}{l}0.015 \\
(0.09)\end{array}$ & $\begin{array}{c}0.383^{* *} \\
(1.98)\end{array}$ & $\begin{array}{c}-0.271^{* * *} \\
(-2.67)\end{array}$ & $\begin{array}{c}-0.275^{* *} \\
(-2.03)\end{array}$ & $\begin{array}{l}-0.027 \\
(-0.14)\end{array}$ \\
\hline Observations & 188 & 184 & 180 & 189 & 185 & 181 \\
\hline $\bar{R}^{2}$ & 0.11 & 0.14 & 0.16 & 0.10 & 0.09 & 0.04 \\
\hline
\end{tabular}


Table 5: - Continued

\begin{tabular}{|c|c|c|c|c|c|c|}
\hline \multicolumn{7}{|c|}{ Panel C: Litigation risk } \\
\hline & \multicolumn{3}{|c|}{$\sum_{j=1}^{k}\left(r_{s, t+j}-r_{c, t+j}\right)$} & \multicolumn{3}{|c|}{$\sigma_{s, t+k}-\sigma_{c, t+k}$} \\
\hline & $k \stackrel{(1)}{=} \mathrm{Y}$ & $\begin{array}{c}(2) \\
k=2 \mathrm{Y}\end{array}$ & $\begin{array}{c}(3) \\
k=3 \mathrm{Y}\end{array}$ & $\begin{array}{c}(4) \\
k=1 \mathrm{Y}\end{array}$ & $\begin{array}{c}(5) \\
k=2 \mathrm{Y}\end{array}$ & $\begin{array}{c}(6) \\
k=3 \mathrm{Y}\end{array}$ \\
\hline Constant & $\begin{array}{c}-0.289^{* *} \\
(-2.35)\end{array}$ & $\begin{array}{l}-0.452 \\
(-1.66)\end{array}$ & $\begin{array}{l}-0.385 \\
(-0.97)\end{array}$ & $\begin{array}{l}-0.107 \\
(-1.10)\end{array}$ & $\begin{array}{l}0.030 \\
(0.14)\end{array}$ & $\begin{array}{l}0.318 \\
(1.35)\end{array}$ \\
\hline$d_{s, t}$ & $\begin{array}{c}1.538^{* * *} \\
(2.70)\end{array}$ & $\begin{array}{c}2.627^{* *} \\
(2.33)\end{array}$ & $\begin{array}{l}2.625 \\
(1.57)\end{array}$ & $\begin{array}{c}0.900^{* *} \\
(2.06)\end{array}$ & $\begin{array}{l}0.667 \\
(0.73)\end{array}$ & $\begin{array}{l}-0.352 \\
(-0.34)\end{array}$ \\
\hline$R_{m, t}-R_{f, t}$ & $\begin{array}{l}-0.148 \\
(-0.95)\end{array}$ & $\begin{array}{l}-0.232 \\
(-1.40)\end{array}$ & $\begin{array}{l}-0.273 \\
(-0.94)\end{array}$ & $\begin{array}{l}-0.131 \\
(-1.00)\end{array}$ & $\begin{array}{l}-0.285 \\
(-1.39)\end{array}$ & $\begin{array}{l}-0.196 \\
(-0.98)\end{array}$ \\
\hline$S M L_{t}$ & $\begin{array}{l}0.673 \\
(1.62)\end{array}$ & $\begin{array}{l}0.625 \\
(0.95)\end{array}$ & $\begin{array}{l}0.489 \\
(0.55)\end{array}$ & $\begin{array}{c}0.660^{* *} \\
(2.20)\end{array}$ & $\begin{array}{l}0.244 \\
(0.54)\end{array}$ & $\begin{array}{l}0.224 \\
(0.44)\end{array}$ \\
\hline$H M L_{t}$ & $\begin{array}{l}0.015 \\
(0.08)\end{array}$ & $\begin{array}{l}-0.258 \\
(-0.61)\end{array}$ & $\begin{array}{l}-0.299 \\
(-0.58)\end{array}$ & $\begin{array}{c}-0.458^{* * *} \\
(-2.74)\end{array}$ & $\begin{array}{c}-0.886^{* * *} \\
(-2.76)\end{array}$ & $\begin{array}{r}-0.479^{*} \\
(-1.76)\end{array}$ \\
\hline$U M D_{t}$ & $\begin{array}{l}0.118 \\
(0.36)\end{array}$ & $\begin{array}{l}0.130 \\
(0.37)\end{array}$ & $\begin{array}{l}0.223 \\
(0.63)\end{array}$ & $\begin{array}{l}0.082 \\
(0.38)\end{array}$ & $\begin{array}{l}-0.020 \\
(-0.10)\end{array}$ & $\begin{array}{l}0.060 \\
(0.37)\end{array}$ \\
\hline$L I Q_{t}$ & $\begin{array}{l}0.067 \\
(0.35)\end{array}$ & $\begin{array}{l}0.068 \\
(0.23)\end{array}$ & $\begin{array}{l}0.415 \\
(1.05)\end{array}$ & $\begin{array}{c}-0.513^{* * *} \\
(-4.79)\end{array}$ & $\begin{array}{l}-0.214 \\
(-1.38)\end{array}$ & $\begin{array}{l}0.002 \\
(0.01)\end{array}$ \\
\hline$\Delta L I T_{t}$ & $\begin{array}{l}0.349 \\
(0.63)\end{array}$ & $\begin{array}{l}0.429 \\
(0.48)\end{array}$ & $\begin{array}{l}0.595 \\
(0.77)\end{array}$ & $\begin{array}{l}0.148 \\
(0.51)\end{array}$ & $\begin{array}{l}-0.057 \\
(-0.16)\end{array}$ & $\begin{array}{l}-0.018 \\
(-0.04)\end{array}$ \\
\hline $\begin{array}{l}\text { Observations } \\
\bar{R}^{2}\end{array}$ & $\begin{array}{c}76 \\
0.14\end{array}$ & $\begin{array}{c}72 \\
0.15\end{array}$ & $\begin{array}{c}68 \\
0.10\end{array}$ & $\begin{array}{c}77 \\
0.30\end{array}$ & $\begin{array}{c}73 \\
0.12\end{array}$ & $\begin{array}{c}69 \\
-0.04\end{array}$ \\
\hline
\end{tabular}

\begin{tabular}{|c|c|c|c|c|c|c|}
\hline \multicolumn{7}{|c|}{ Panel D: Fama-French (five factors) } \\
\hline & \multicolumn{3}{|c|}{$\sum_{j=1}^{k}\left(r_{s, t+j}-r_{c, t+j}\right)$} & \multicolumn{3}{|c|}{$\sigma_{s, t+k}-\sigma_{c, t+k}$} \\
\hline & $\begin{array}{c}(1) \\
k=1 \mathrm{Y}\end{array}$ & $\begin{array}{c}(2) \\
k=2 \mathrm{Y}\end{array}$ & $\begin{array}{c}(3) \\
k=3 \mathrm{Y}\end{array}$ & $\begin{array}{c}(4) \\
k=1 \mathrm{Y}\end{array}$ & $\begin{array}{c}(5) \\
k=2 \mathrm{Y}\end{array}$ & $\begin{array}{c}(6) \\
k=3 \mathrm{Y}\end{array}$ \\
\hline Constant & $\begin{array}{c}-0.182^{* *} \\
(-2.52)\end{array}$ & $\begin{array}{c}-0.323^{* * *} \\
(-3.04)\end{array}$ & $\begin{array}{c}-0.428^{* * *} \\
(-2.75)\end{array}$ & $\begin{array}{c}-0.129^{*} \\
(-1.71)\end{array}$ & $\begin{array}{l}-0.146 \\
(-1.28)\end{array}$ & $\begin{array}{l}-0.141 \\
(-0.94)\end{array}$ \\
\hline$d_{s}$ & $\begin{array}{c}1.130^{* * * *} \\
(2.81)\end{array}$ & $\begin{array}{c}2.071^{* * * *} \\
(3.79)\end{array}$ & $\begin{array}{c}2.826^{* * *} \\
(3.69)\end{array}$ & $\begin{array}{c}0.946^{* *} \\
(2.38)\end{array}$ & $\begin{array}{c}1.310^{* *} \\
(2.26)\end{array}$ & $\begin{array}{c}1.537^{* * *} \\
(2.09)\end{array}$ \\
\hline$R_{m, t}-R_{f, t}$ & $\begin{array}{c}-0.177^{*} \\
(-1.70)\end{array}$ & $\begin{array}{l}-0.205 \\
(-1.39)\end{array}$ & $\begin{array}{l}-0.265 \\
(-1.29)\end{array}$ & $\begin{array}{l}0.036 \\
(0.33)\end{array}$ & $\begin{array}{l}0.186 \\
(1.14)\end{array}$ & $\begin{array}{c}0.341^{*} \\
(1.87)\end{array}$ \\
\hline$S M L_{t}$ & $\begin{array}{c}0.288^{* *} \\
(2.20)\end{array}$ & $\begin{array}{l}0.250 \\
(1.16)\end{array}$ & $\begin{array}{l}0.311 \\
(0.84)\end{array}$ & $\begin{array}{l}0.057 \\
(0.39)\end{array}$ & $\begin{array}{l}-0.168 \\
(-0.69)\end{array}$ & $\begin{array}{l}-0.430 \\
(-1.15)\end{array}$ \\
\hline$H M L_{t}$ & $\begin{array}{c}-0.389^{*} \\
(-1.79)\end{array}$ & $\begin{array}{c}-0.663^{*} \\
(-1.97)\end{array}$ & $\begin{array}{l}-0.424 \\
(-0.95)\end{array}$ & $\begin{array}{c}-0.447^{*} \\
(-1.79)\end{array}$ & $\begin{array}{c}-0.734^{* *} \\
(-2.05)\end{array}$ & $\begin{array}{l}-0.514 \\
(-1.06)\end{array}$ \\
\hline$R M W_{t}$ & $\begin{array}{l}-0.307 \\
(-1.20)\end{array}$ & $\begin{array}{l}-0.374 \\
(-0.94)\end{array}$ & $\begin{array}{l}-0.310 \\
(-0.60)\end{array}$ & $\begin{array}{l}-0.039 \\
(-0.16)\end{array}$ & $\begin{array}{l}0.041 \\
(0.14)\end{array}$ & $\begin{array}{l}0.248 \\
(0.72)\end{array}$ \\
\hline$C M A_{t}$ & $\begin{array}{l}0.507 \\
(1.59)\end{array}$ & $\begin{array}{l}0.670 \\
(1.30)\end{array}$ & $\begin{array}{l}0.241 \\
(0.40)\end{array}$ & $\begin{array}{l}0.298 \\
(0.96)\end{array}$ & $\begin{array}{l}0.518 \\
(1.15)\end{array}$ & $\begin{array}{l}0.554 \\
(0.90)\end{array}$ \\
\hline $\begin{array}{l}\text { Observations } \\
\bar{R}^{2}\end{array}$ & $\begin{array}{l}200 \\
0.12\end{array}$ & $\begin{array}{l}196 \\
0.16\end{array}$ & $\begin{array}{l}192 \\
0.14\end{array}$ & $\begin{array}{l}201 \\
0.07\end{array}$ & $\begin{array}{l}197 \\
0.08\end{array}$ & $\begin{array}{l}193 \\
0.05\end{array}$ \\
\hline
\end{tabular}


Table 6: Analysis of unconditional return and volatility spreads (alternative dividend share measures) This table reports estimates from regressions of return and volatility spreads between the sin and the non-sin comparable portfolio on alternative measures of the dividend share of the sin portfolio $d_{s}$. Columns 1 through 3 analyze the return spread. Columns 4 through 6 analyze the volatility spread. Columns 1 and 4 show results at the one-year investment horizon. Columns 2 and 5 show results at the two-year investment horizon. Columns 3 and 6 show results at the three-year investment horizon. In Panel A (sample period 1965Q1:2015Q4), $d_{s}$ is computed from dividend-only payments from CRSP. In Panel B (sample period 1965Q1:2015Q4), $d_{s}$ is computed from dividend payments and repurchases from Compustat (Skinner, 2008). Panel C uses the quantity-based dividend share $\tilde{d}_{s}$, which is adjusted for the relative price of sin and non-sin comparable goods and is available from 1986Q1 (see Appendix C.2). Portfolio returns are value-weighted. All the variables are at quarterly frequency. The $t$-statistics (in parentheses) are computed computed using Newey-West standard errors with four lags. Significance at the $10 \%, 5 \%$, and $1 \%$ levels are indicated by ${ }^{*},{ }^{* *},{ }^{* * *}$, respectively. Refer to Appendix C.1 for details on portfolio construction.

\begin{tabular}{|c|c|c|c|c|c|c|}
\hline \multicolumn{7}{|c|}{ Panel A: Dividends only } \\
\hline & \multicolumn{3}{|c|}{$\sum_{j=1}^{k}\left(r_{s, t+j}-r_{c, t+j}\right)$} & \multicolumn{3}{|c|}{$\sigma_{s, t+k}-\sigma_{c, t+k}$} \\
\hline & $\begin{array}{c}(1) \\
k=1 \mathrm{Y}\end{array}$ & $\begin{array}{c}(2) \\
k=2 \mathrm{Y}\end{array}$ & $\begin{array}{c}(3) \\
k=3 \mathrm{Y}\end{array}$ & $\begin{array}{c}(4) \\
k=1 \mathrm{Y}\end{array}$ & $\begin{array}{c}(5) \\
k=2 \mathrm{Y}\end{array}$ & $\begin{array}{c}(6) \\
k=3 \mathrm{Y}\end{array}$ \\
\hline Constant & $\begin{array}{c}-0.108^{*} \\
(-1.84)\end{array}$ & $\begin{array}{c}-0.202^{* *} \\
(-2.04)\end{array}$ & $\begin{array}{c}-0.293^{* *} \\
(-2.26)\end{array}$ & $\begin{array}{l}-0.018 \\
(-0.36)\end{array}$ & $\begin{array}{l}-0.062 \\
(-0.70)\end{array}$ & $\begin{array}{l}-0.128 \\
(-1.10)\end{array}$ \\
\hline$d_{s, t}$ (dividend) & $\begin{array}{c}0.757^{* *} \\
(2.36)\end{array}$ & $\begin{array}{c}1.465^{* * *} \\
(2.76)\end{array}$ & $\begin{array}{c}2.158^{* * *} \\
(3.20)\end{array}$ & $\begin{array}{l}0.370 \\
(1.50)\end{array}$ & $\begin{array}{c}0.887^{* *} \\
(2.00)\end{array}$ & $\begin{array}{c}1.531^{* * *} \\
(2.69)\end{array}$ \\
\hline $\begin{array}{l}\text { Observations } \\
\bar{R}^{2}\end{array}$ & $\begin{array}{l}200 \\
0.06\end{array}$ & $\begin{array}{l}196 \\
0.11\end{array}$ & $\begin{array}{l}192 \\
0.14\end{array}$ & $\begin{array}{l}201 \\
0.01\end{array}$ & $\begin{array}{l}197 \\
0.04\end{array}$ & $\begin{array}{l}193 \\
0.08\end{array}$ \\
\hline
\end{tabular}

\begin{tabular}{|c|c|c|c|c|c|c|}
\hline \multicolumn{7}{|c|}{ Panel B: Compustat } \\
\hline & \multicolumn{3}{|c|}{$\sum_{j=1}^{k}\left(r_{s, t+j}-r_{c, t+j}\right)$} & \multicolumn{3}{|c|}{$\sigma_{s, t+k}-\sigma_{c, t+k}$} \\
\hline & $\begin{array}{c}(1) \\
k=1 \mathrm{Y}\end{array}$ & $\begin{array}{c}(2) \\
k=2 \mathrm{Y}\end{array}$ & $\begin{array}{c}(3) \\
k=3 \mathrm{Y}\end{array}$ & $\begin{array}{c}(4) \\
k=1 \mathrm{Y}\end{array}$ & $\begin{array}{c}(5) \\
k=2 \mathrm{Y}\end{array}$ & $\begin{array}{c}(6) \\
k=3 \mathrm{Y}\end{array}$ \\
\hline Constant & $\begin{array}{l}-0.139 \\
-1.39)\end{array}$ & $\begin{array}{l}-0.132 \\
(-0.93)\end{array}$ & $\begin{array}{l}-0.153 \\
(-0.76)\end{array}$ & $\begin{array}{c}-0.314^{* * *} \\
(-4.17)\end{array}$ & $\begin{array}{c}-0.286^{* *} \\
(-2.20)\end{array}$ & $\begin{array}{l}-0.260 \\
(-1.45)\end{array}$ \\
\hline$d_{s, t}$ (Compustat) & $\begin{array}{l}0.898 \\
(1.65)\end{array}$ & $\begin{array}{l}1.056 \\
(1.37)\end{array}$ & $\begin{array}{l}1.365 \\
(1.27)\end{array}$ & $\begin{array}{c}1.908^{* * *} \\
(4.80)\end{array}$ & $\begin{array}{c}2.033^{* * *} \\
(3.07)\end{array}$ & $\begin{array}{c}2.181^{* *} \\
(2.48)\end{array}$ \\
\hline Observations & 200 & 196 & 192 & 201 & 197 & 193 \\
\hline $\bar{R}^{2}$ & 0.03 & 0.02 & 0.02 & 0.19 & 0.10 & 0.07 \\
\hline
\end{tabular}

\begin{tabular}{lcccccccc}
\hline Panel C: Quantity-based & \multicolumn{3}{c}{} & & & \\
\hline & \multicolumn{3}{c}{$\sum_{j=1}^{k}\left(r_{s, t+j}-r_{c, t+j}\right)$} & & \multicolumn{3}{c}{$\sigma_{s, t+k}-\sigma_{c, t+k}$} \\
\cline { 2 - 4 } \cline { 6 - 8 } & $(1)$ & $(2)$ & & $(3)$ & & $(4)$ & $(5)$ & $(6)$ \\
& $k=1 \mathrm{Y}$ & $k=2 \mathrm{Y}$ & $k=3 \mathrm{Y}$ & & $k=1 \mathrm{Y}$ & $k=2 \mathrm{Y}$ & $k=3 \mathrm{Y}$ \\
\hline Constant & -0.026 & 0.012 & 0.068 & & -0.051 & -0.020 & 0.046 \\
& $(-0.40)$ & $(0.13)$ & $(0.47)$ & & $(-1.11)$ & $(-0.24)$ & $(0.42)$ \\
$\tilde{d}_{s, t}$ & 0.229 & 0.250 & 0.206 & & $0.462^{* * *}$ & $0.655^{* *}$ & $0.721^{* *}$ \\
& $(1.02)$ & $(0.77)$ & $(0.43)$ & & $(2.83)$ & $(2.41)$ & $(2.01)$ \\
\hline Observations & 116 & 112 & 108 & & 117 & 113 & 109 \\
$\bar{R}^{2}$ & 0.00 & -0.00 & -0.01 & & 0.09 & 0.09 & 0.08 \\
\hline
\end{tabular}




\section{Appendix for \\ "Pricing Sin Stocks: \\ Ethical Preference vs. Risk Aversion"}

\section{A Proofs}

Proof of Proposition 1. The maximization problem (5) implies

$$
\left(\frac{\pi_{s}}{\pi_{c}}\right)^{\beta}\left(\frac{D_{s, t}}{D_{c, t}}\right)^{-\gamma}=\frac{p_{s, t}}{p_{c, t}}
$$

The numeraire, which is a basket $\left(\alpha D_{s, t},(1-\alpha) D_{c, t}\right)$ with $\alpha \in[0,1]$, has unity price, i.e.

$$
\alpha p_{s, t}+(1-\alpha) p_{c, t}=1 \text {. }
$$

The two equations above give the results.

Proof of Proposition 2. Given the expression or $S_{s, t}$ given in equation (8), we have

$$
\begin{aligned}
S_{s, t} & =p_{s, t} D_{s, t} \mathbb{E}_{t} \int_{t}^{\infty}\left[e^{-\rho(u-t)}\left(\frac{D_{s, u}}{D_{c, t}}\right)^{(1-\gamma)}\right] d u \\
& =p_{s, t} D_{s, t} \int_{t}^{\infty} \mathbb{E}_{t} e^{\left[-\rho+(1-\gamma)\left(\nu_{s}-\frac{1}{2} \phi_{s}^{2}\right)\right](u-t)+(1-\gamma) \phi_{s}\left(B_{s, u}-B_{s, t}\right)} d u \\
& =p_{s, t} D_{s, t} \int_{t}^{\infty} e^{-\left[\rho-(1-\gamma)\left(\nu_{s}-\frac{1}{2} \phi_{s}^{2}\right)-\frac{1}{2}(1-\gamma)^{2} \phi_{s}^{2}\right](u-t)} d u \\
& =\frac{p_{s, t} D_{s, t}}{\Gamma_{s}}
\end{aligned}
$$

with

$$
\Gamma_{s}=\rho+(\gamma-1)\left(\nu_{s}-\frac{\phi_{s}^{2}}{2}\right)-\frac{1}{2}(1-\gamma)^{2} \phi_{s}^{2} .
$$

$S_{c, t}$ and $\Gamma_{c}$ are obtained using the same procedure.

Proof of Proposition 3. From Proposition 2 we have

$$
\frac{d S_{i, t}}{S_{i, t}}=\frac{d p_{i, t}}{p_{i, t}}+\frac{d D_{i, t}}{D_{i, t}}+\frac{d\left[p_{i, t} D_{i, t}\right]}{p_{i, t} D_{i, t}}, \quad i=s, c .
$$


The equilibrium relative prices of consumption goods (7) can be rewritten as

$$
\begin{aligned}
p_{s, t} & =\frac{\pi_{s}^{\beta} D_{s, t}^{-\gamma}}{\alpha \pi_{s}^{\beta} D_{s, t}^{-\gamma}+(1-\alpha) \pi_{c}^{\beta} D_{c, t}^{-\gamma}}=\frac{1}{\alpha+(1-\alpha) x^{\beta} y_{t}^{\gamma}} \\
p_{c, t} & =\frac{x^{\beta} y_{t}^{\gamma}}{\alpha+(1-\alpha) x^{\beta} y_{t}^{\gamma}}=x^{\beta} y_{t}^{\gamma} p_{s, t},
\end{aligned}
$$

where we have used $x:=\frac{\pi_{c}}{\pi_{s}}$ and $y_{t}:=\frac{D_{s, t}}{D_{c, t}}$. Given (1) we have

$$
d y_{t}=y_{t}\left(\nu_{s}-\nu_{c}+\phi_{c}^{2}\right) d t+y_{t}\left(\phi_{s} d B_{s, t}-\phi_{c} d B_{c, t}\right)
$$

Using the above results we can calculate $\frac{d p_{s, t}}{p_{s, t}}$ :

$$
\begin{aligned}
d p_{s, t}= & p_{s, t}\left[-\frac{(1-\alpha) \gamma x^{\beta} y_{t}^{\gamma-1}}{\alpha+(1-\alpha) x^{\beta} y_{t}^{\gamma}} d y_{t}\right] \\
& +\frac{1}{2}\left\{p_{s, t}\left[-\frac{(1-\alpha) \gamma(\gamma-1) x^{\beta} y_{t}^{\gamma-2}}{\alpha+(1-\alpha) x^{\beta} y_{t}^{\gamma}}+\frac{2\left((1-\alpha) \gamma x^{\beta} y_{t}^{\gamma-1}\right)^{2}}{\left(\alpha+(1-\alpha) x^{\beta} y_{t}^{\gamma}\right)^{2}}\right]\left(d y_{t}\right)^{2}\right\} \\
= & -(1-\alpha) \gamma p_{s, t} p_{c, t} \frac{d y_{t}}{y_{t}}-\frac{1}{2}(1-\alpha) \gamma p_{s, t} p_{c, t}\left[(\gamma-1)-2(1-\alpha) \gamma p_{c, t}\right] \frac{\left(d y_{t}\right)^{2}}{y_{t}^{2}}
\end{aligned}
$$

where the second-order infinitesimal term is $\left(d y_{t}\right)^{2}=y_{t}^{2}\left(\phi_{s}^{2}+\phi_{c}^{2}\right) d t$. Plugging this term and (A.3) in the expression above and rearranging we get

$$
\frac{d p_{s, t}}{p_{s, t}}=(1-\alpha) p_{c, t} \gamma\left[-\Lambda_{t} d t-\phi_{s} d B_{s, t}+\phi_{c} d B_{c, t}\right]
$$

with

$$
\Lambda_{t}:=\nu_{s}-\nu_{c}+\phi_{c}^{2}+\frac{1}{2}(\gamma-1)\left(\phi_{s}^{2}+\phi_{c}^{2}\right)-(1-\alpha) \gamma p_{c, t}\left(\phi_{s}^{2}+\phi_{c}^{2}\right)
$$

Similarly for $\frac{d p_{c, t}}{p_{c, t}}$ :

$$
d p_{c, t}=\alpha \gamma p_{c, t} p_{s, t} \frac{d y_{t}}{y_{t}}+\frac{1}{2} \alpha \gamma p_{c, t} p_{s, t}\left[(\gamma-1)-2(1-\alpha) \gamma p_{c, t}\right] \frac{\left(d y_{t}\right)^{2}}{y_{t}^{2}}
$$

or equivalently

$$
\frac{d p_{c, t}}{p_{c, t}}=\alpha \gamma p_{s, t}\left[\Lambda_{t} d t-\phi_{s} d B_{s, t}+\phi_{c} d B_{c, t}\right]
$$


Hence, we have

$$
\begin{aligned}
& \frac{d\left[p_{s, t}, D_{s, t}\right]}{p_{s, t} D_{s, t}}=-(1-\alpha) p_{c, t} \gamma \phi_{s}^{2} d t \\
& \frac{d\left[p_{c, t}, D_{c, t}\right]}{p_{c, t} D_{c, t}}=\alpha p_{s, t} \gamma \phi_{c}^{2} d t .
\end{aligned}
$$

Replacing (A.7), (1), (A.5), and (A.6) into (A.1) gives us the desired expressions for $d S_{s, t}$ and $d S_{s, t}$. Matching equation (3) with the the dynamics of prices reported in Proposition 3 , we obtain

$$
\begin{aligned}
\sigma_{s, t}^{s} & =\left[1-(1-\alpha) \gamma p_{c, t}\right] \phi_{s} \\
\sigma_{c, t}^{s} & =(1-\alpha) p_{c, t} \gamma \phi_{c} \\
\sigma_{s, t}^{c} & =-\alpha \gamma p_{s, t} \phi_{s} \\
\sigma_{c, t}^{c} & =\left[1+\alpha \gamma p_{s, t}\right] \phi_{c}
\end{aligned}
$$

and the instantaneous standard deviation of stocks is therefore

$$
\begin{aligned}
& s t d_{s, t}=\sqrt{\left(\sigma_{s, t}^{s}\right)^{2}+\left(\sigma_{c, t}^{s}\right)^{2}} \\
& s t d_{c, t}=\sqrt{\left(\sigma_{s, t}^{c}\right)^{2}+\left(\sigma_{c, t}^{c}\right)^{2}}
\end{aligned}
$$

Proof of Proposition 4. In our model markets are complete and by standard arguments we have

$$
\mu_{i, t}-r_{t}=\mathbb{E}_{t}\left(\frac{d S_{i, t}}{S_{i, t}}\right)+\frac{p_{i, t} D_{i, t}}{S_{i, t}}-r d t=-\operatorname{Cov}\left(\frac{d S_{i, t}}{S_{i, t}}, \frac{d \lambda_{t}}{\lambda_{t}}\right) \quad i=s, c,
$$

where

$$
\begin{aligned}
\frac{d \lambda_{t}}{\lambda_{t}}= & {\left[-\rho-\gamma \alpha p_{s, t} \nu_{s}-\gamma(1-\alpha) p_{c, t} \nu_{c}+\frac{1}{2} \gamma(\gamma+1)\left(\alpha p_{s, t} \phi_{s}^{2}+(1-\alpha) p_{c, t} \phi_{c}^{2}\right)\right] d t } \\
& -\gamma \alpha p_{s, t} \phi_{s} d B_{s, t}-\gamma(1-\alpha) p_{c, t} \phi_{c} d B_{c, t} .
\end{aligned}
$$

The quantity $\operatorname{Cov}\left(\frac{d S_{i, t}}{S_{i, t}}, \frac{d \lambda_{t}}{\lambda_{t}}\right)$ is computed by using the results of Proposition 3. The formula for the return spread uses the relation

$$
\alpha p_{s, t}(1-\alpha) p_{c, t}=\alpha p_{s, t}\left(1-\alpha p_{s, t}\right)=\left[1-(1-\alpha) p_{c, t}\right](1-\alpha) p_{c, t}
$$

which follows from the fact that $\alpha p_{s, t}+(1-\alpha) p_{c, t}=1$. 


\section{B Alternative calibration}

In Figure B.1 and Figure B.2, we report the results from an alternative calibration exercise, where we account for different fundamentals across the two firms in our model. In this case, we set the payout parameters to their empirically observed values, that is, $\nu_{s}=4 \times 0.010, \nu_{c}=4 \times 0.006, \phi_{s}=\sqrt{4} \times 0.156$, and $\phi_{c}=\sqrt{4} \times 0.098$. In addition, we set $\alpha=0.192$, consistent with the observed average share of the total payout of sin companies (Panel D of Table 1).

\section{Data}

\section{C.1 Portfolio construction}

We follow Hong and Kacperczyk (2009) and define sin companies as those operating in the following industries.

- Alcoholic beverages (Fama-French industry 4): SIC codes 2080-2085. ${ }^{25}$

- Smoke products (Fama-French industry 5): SIC codes 2100-2199.

- Gaming: NAICS codes 7132, 71321, 713210, 71329, 713290, 72112, and 721120.

For our extended sin portfolio, we include also companies active in the following industries.

- Distribution of alcoholic beverages: SIC codes 5180-5189, 5813, and 5921.

- Distribution of smoke products: SIC codes 5194 and 5993.

Non-sin comparable companies are those operating in the following industries.

- Food (Fama-French industry 2): SIC codes 2000-2009, 2010-2019, 2020-2029, 20302039, 2040-2046, 2050-2059, 2060-2063, 2070-2079, 2090-2092, 2095, and 2098-2099.

- Soda (Fama-French industry 3): SIC codes 2064-2068, 2086, 2087, 2096, and 2097.

- Fun (Fama-French industry 7): SIC codes 7800-7829, 7830-7833, 7840-7841, 7900, 7910-7911, 7920-7929, 7930-7933, 7940-7949, 7980, and 7990-7999.

- Meals (Fama-French industry 43, excluding drinking places): SIC codes 5800-5812, 5814-5819, 5820-5829, 5890-5899, 7000, 7010-7019, 7040-7049, and 7213-7213.

We identify companies operating in the industries above using both firm-level industry codes from CRSP, and primary and secondary segment-level industry codes from Compustat Segment files. Because Compustat Segment files are available only starting in 1976, we backfill segment industry codes over the pre-1976 period, in line with Hong and Kacperczyk (2009).

We manually checked the sin stocks obtained through this procedure and removed those that are not involved in sinful activities. This is the case of firms that are assigned the general SIC code for beverages 2080 but do not actually produce alcoholic beverages

\footnotetext{
${ }^{25}$ Fama-French industry groups refer to the 48-industry classification by Fama and French (1997).
} 
(e.g., the Coca-Cola Bottling Company). Moreover, firms that operate both in the sin industries and non-sin comparable industries above are classified as sinful.

Finally, we checked our list of sin companies against the list made available by Hong and Kacperczyk (2009) for the period 1962-2003. ${ }^{26}$ Our algorithm is able to capture 178 out of the 184 companies included in their list. We manually added the remaining six companies to our sin portfolio.

\section{C.2 Good-price adjustment}

To compute the quantity-based dividend share measure $\tilde{d}_{s}$, we deflate repurchase-adjusted dividend payments of the sin and non-sin comparable portfolios using the price of the corresponding goods.

We use seasonally adjusted series on CPI components from FRED to compute the relative prices $p_{s}$ and $p_{c}$ of sin and non-sin comparable goods. The sin goods price index is computed as the average of the prices of the following CPI components:

- Alcoholic beverages (CUSR0000SAF116, available from 1967Q1);

- Tobacco and smoking products (CUSR0000SEGA, available from 1986Q1).

We are thus able to construct a time series of $p_{s}$ starting in 1986Q1. The time series of prices of gaming products and services is not available.

The non-sin comparable goods price index is computed as the average of the prices of the following CPI components:

- Recreation (CPIRECSL, available from 1993Q1);

- Food at home (CUSR0000SAF11, available from 1952Q1);

- Food away from home (CUSR0000SEFV, available from 1953Q1);

- Lodging away from home (CUSR0000SEHB, available from 1998Q1).

We compute the time series of $p_{c}$ starting in 1986Q1, and account for the different CPI components in the average as soon as they become available.

\section{C.3 Cyclicality of sin good consumption}

As argued above, stocks of sin companies may have low exposure to aggregate risk because of the addictive nature of the goods they produce. To support this conjecture, here we analyze the cyclical properties of sin good consumption. Using data from FRED, we look at the correlation between the growth of sin good consumption and two business cycle variables, namely GDP (GDPC1) growth and aggregate consumption (PCECA) growth.

Data on personal consumption of sin goods are available at annual frequency. Sin good consumption is obtained by summing up the following components:

- Alcoholic beverages (DAOPRC1A027NBEA);

- Tobacco (DTOBRC1A027NBEA);

\footnotetext{
${ }^{26}$ See http://www.columbia.edu/ hh2679/sinstocks.pdf.
} 
- Gambling (DGAMRC1A027NBEA).

We contrast the cyclical properties of sin goods against those of comparable goods, where consumption of the latter is obtained by summing up the following components:

- Recreation services (DRCARC1A027NBEA);

- Food services and accommodation away from home (DFSARC1A027NBEA);

- Food and nonalcoholic beverages at home (DTFDRC1A027NBEA).

Given that durability correlates positively with cyclicality of a given good consumption (Gomes, Kogan, and Yogo, 2009), we also compare sin goods vis a vis durable goods (PCDGA). All the series above are available throughout the sample period (1965-2015) and expressed in real terms. We conduct the analysis at annual frequency.

Table C.1 reports the coefficient estimates of regressions of consumption growth of different goods on GDP growth (Panel A) and aggregate consumption growth (Panel B). We observe that sin good consumption, while positively correlated with business cycle variables, is significantly less cyclical than durable good consumption. Sin goods also appear to be less cyclical than comparable goods in both Panel A and Panel B, but the difference is statistically significant only when using aggregate consumption as explanatory variable, which is not surprising since our comparable goods are nondurable goods. 

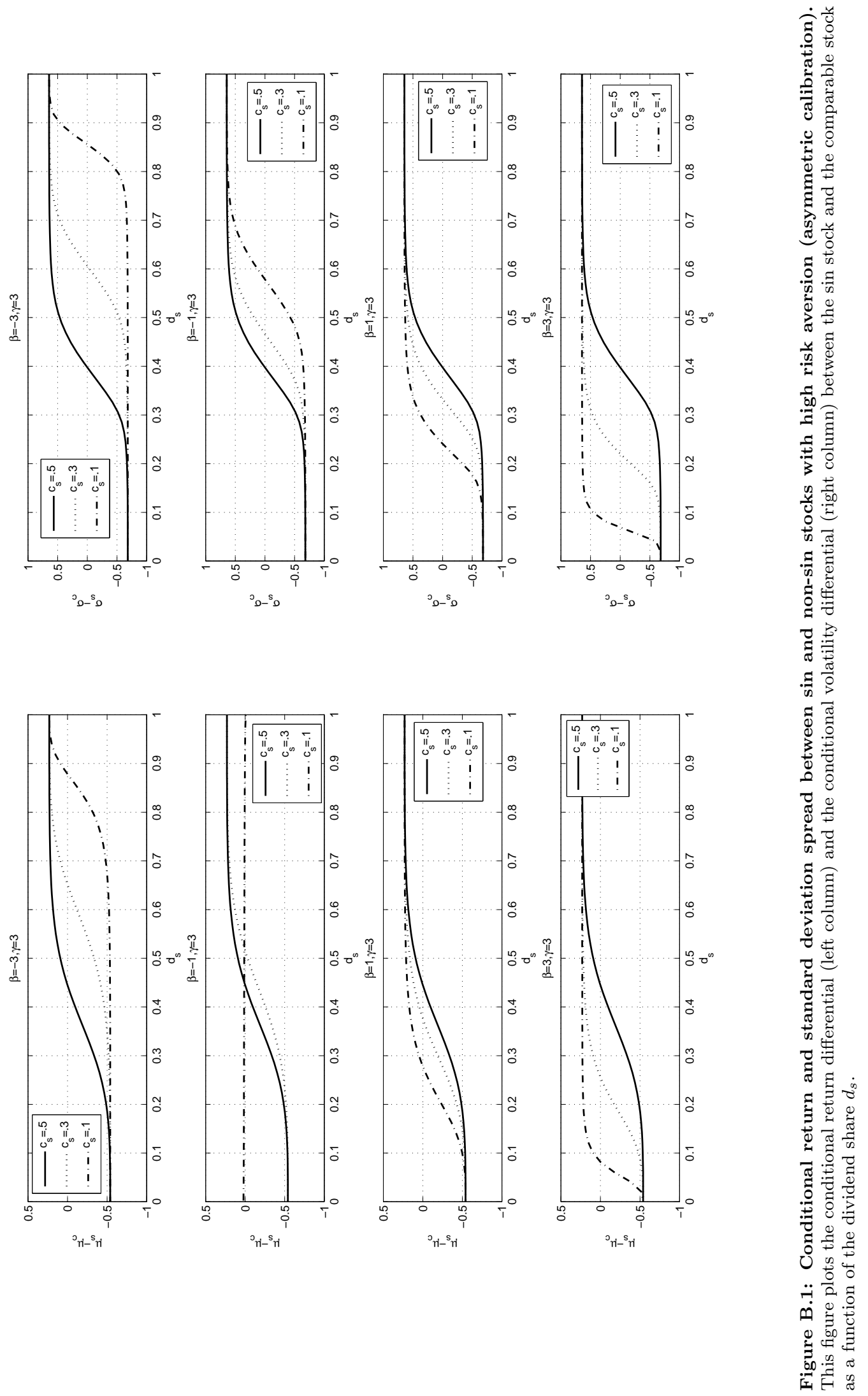


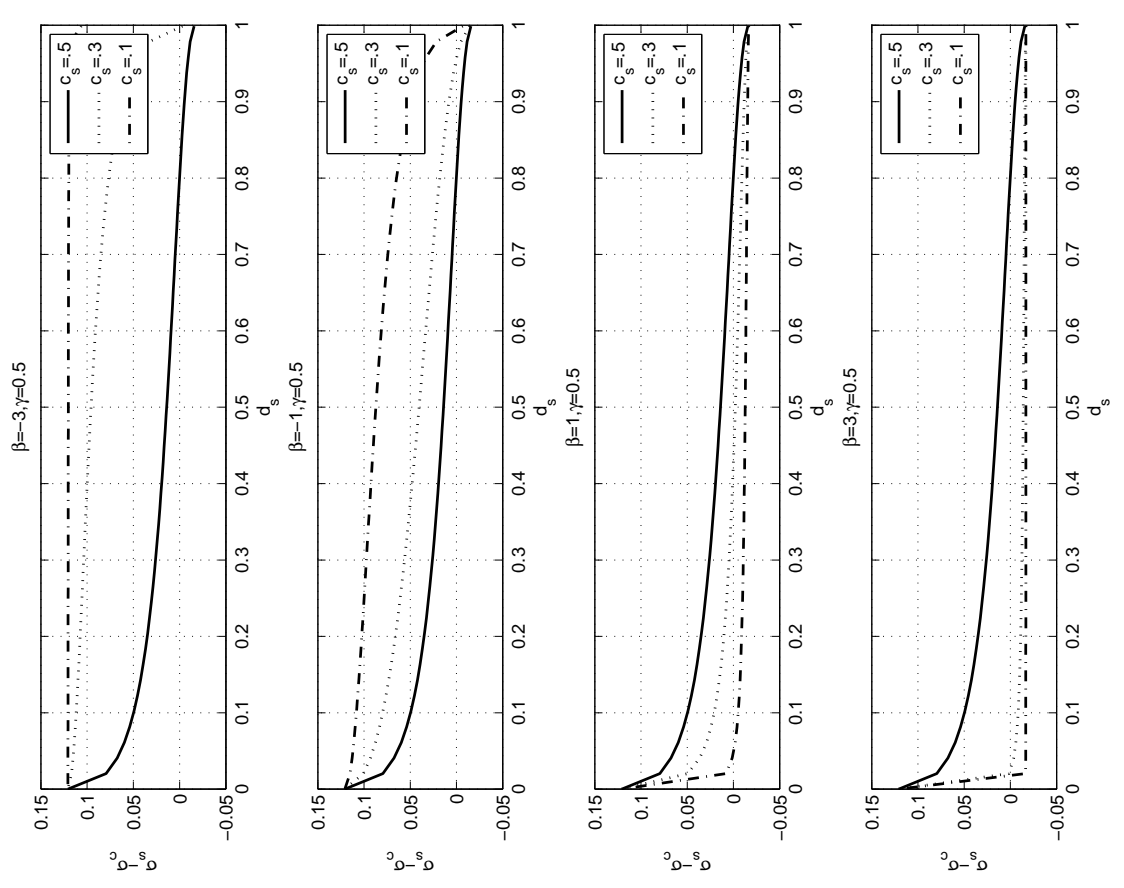

寻

天े

है.

ฮั

.

:

बृ

क्ष

ฮั

离

3

营产

눌

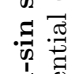

:

สี

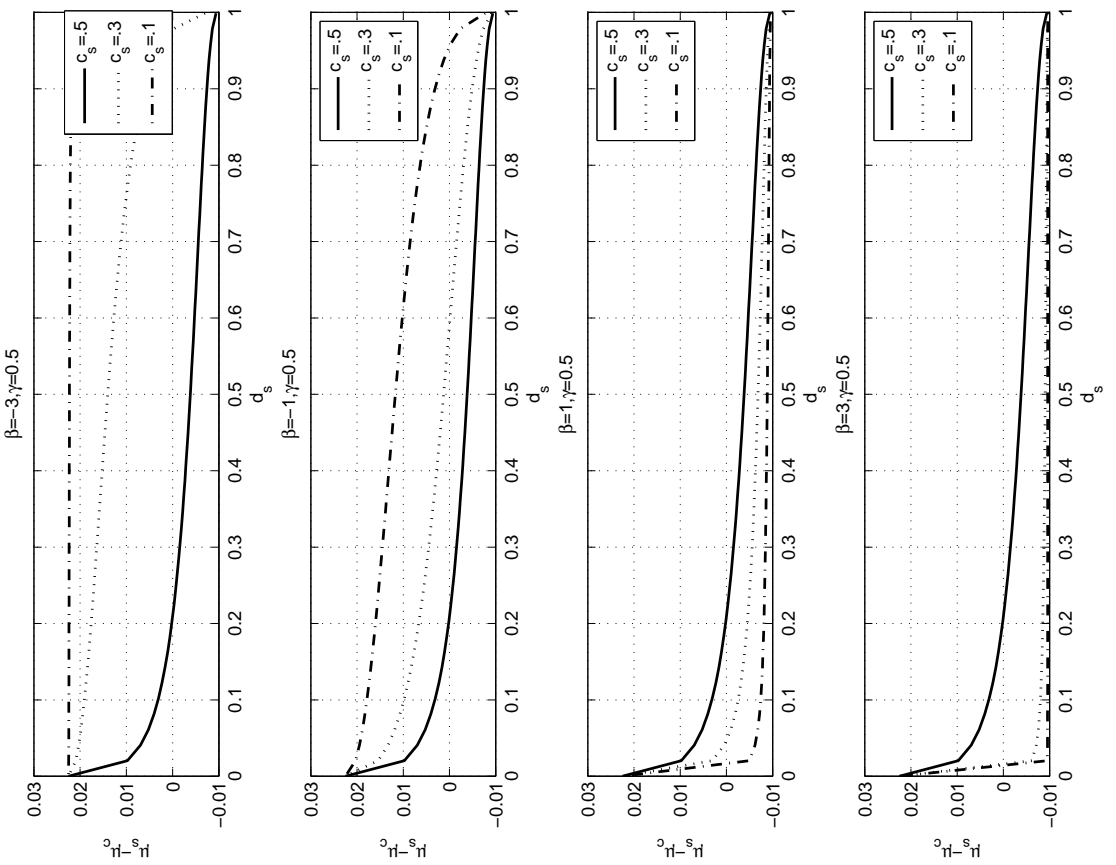

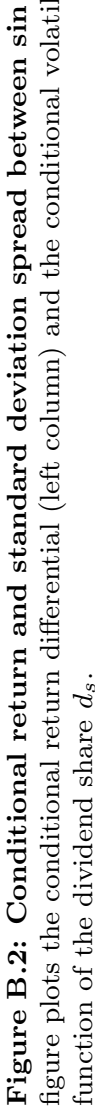


Table C.1: Cyclicality of sin good consumption

This table reports estimates from regressions of real consumption growth of different goods on measures of the business cycle. Panel A uses real GDP growth as explanatory variable. Panel B uses real aggregate consumption growth as explanatory variable. The two panels follow the same structure. Column 1 analyzes the growth of real consumption of sin goods. Column 2 analyzes the growth of real consumption of comparable goods. Column 3 analyzes the growth of real consumption of durable goods. All the variables are at annual frequency and the sample period is from 1965 to 2015 . The last row reports the Chi-square $p$-value for the Wald test of differences in the coefficient of the explanatory variable. This test is performed with respect to sin goods. The $t$-statistics (in parentheses) are computed computed using Huber-White standard errors. Significance at the $10 \%, 5 \%$, and $1 \%$ levels are indicated by ${ }^{*},{ }^{* *},{ }^{* * *}$, respectively. Refer to Appendix C. 3 for details on variable construction.

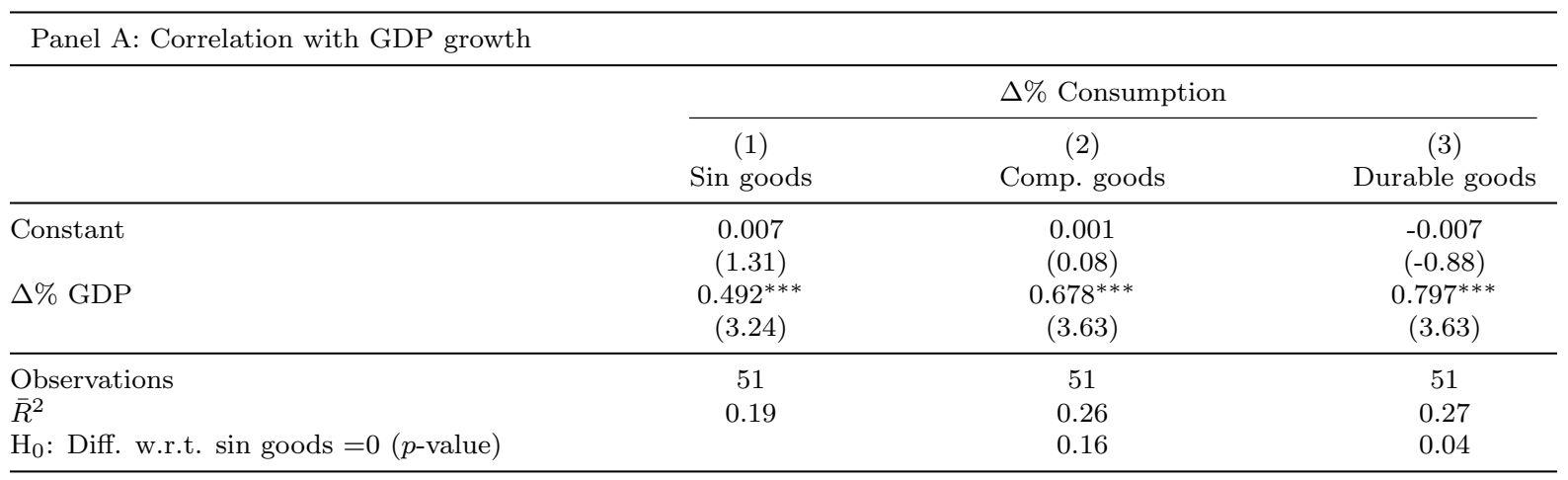

\begin{tabular}{lccc}
\hline Panel B: Correlation with aggregate consumption growth \\
\hline & \multicolumn{3}{c}{$\Delta \%$ Consumption } \\
\cline { 2 - 4 } & Sin goods & $(2)$ & $(3)$ \\
& 0.002 & $-0.007^{* * *}$ & Durable goods \\
\hline Constant & $(0.47)$ & $(-3.11)$ & $-0.015^{* * *}$ \\
$\Delta \%$ Aggregate consumption & $0.730^{* * *}$ & $1.030^{* * *}$ & $(-5.03)$ \\
& $(7.33)$ & $(16.80)$ & $1.147^{* * *}$ \\
\hline Observations & 51 & 51 & $(16.22)$ \\
$\bar{R}^{2}$ & 0.55 & 0.79 & 51 \\
$\mathrm{H}_{0}$ : Diff. w.r.t. sin goods $=0(p$-value $)$ & & 0.00 & 0.73 \\
\hline
\end{tabular}




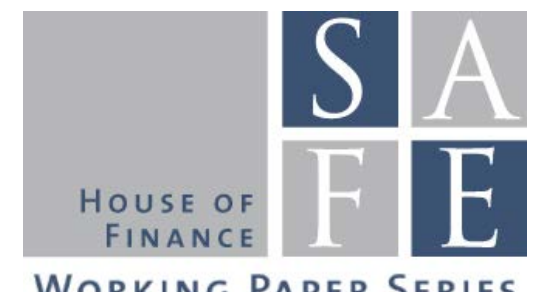

Working PAPER SERIES

\section{Recent Issues}

No. 215 Zsuzsa R. Huszár, Zorka Simon

No. 214 Edin Ibrocevic, Matthias Thiemann

No. 213 Klaus Gugler, Michael Weichselbaumer, Christine Zulehner

No. 212 Henning Hesse

No. 211 Thomas Mosk

No. 210 Darien Huang, Christian Schlag, Ivan Shaliastovich, Julian Thimme

No. 209 Eren Gürer, Alfons J. Weichenrieder

No. 208 Roberto Casarin, Michele Costola, Erdem Yenerdag

No. 207 Claes Bäckman, Tobin Hanspal

No. 206 Loriana Pelizzon, Anjan Thakor, Calebe de Roure

No. 205 Horst Entorf, Jia Hou

No. 204 Loriana Pelizzon, Matteo Sottocornola

No. 203 Florian Hett, Felix Schmidt
The Pricing Implications of the Oligopolistic Securities Lending Market: A Beneficial Owner Perspective

All Economic Ideas are Equal, but Some are more Equal than Others: A Differentiated Perspective on Macroprudential Ideas and their Implementation

Effects of Government Spending on Employment: Evidence from Winners and Runners-up in Procurement Auctions

Incentive Effects from Write-down CoCo Bonds: An Empirical Analysis

Bargaining with a Bank

Volatility-of-Volatility Risk

Pro-rich Inflation in Europe: Implications for the Measurement of Inequality

Financial Bridges and Network Communities

The Geography of Alternative Work

P2P Lending versus Banks: Cream Skimming or Bottom Fishing?

Financial Education for the Disadvantaged? A Review

The Impact of Monetary Policy Interventions on the Insurance Industry

Pushing Through or Slacking Off? Heterogeneity in the Reaction to Rank Feedback 